\title{
Microstrip Antenna Analysis with Aid of Ultra Wide Band Applications
}

Parthiban N ( $\sim$ parthibannece@gmail.com )

B S Abdur Rahman Crescent Institute of Science \& Technology

Mohamed Ismail M

B S Abdur Rahman Crescent Institute of Science \& Technology

\section{Research Article}

Keywords: Bandwidth, Ground Plane (GP), Microstrip patch antenna (MPA), Operating frequency, Spectrum, and Ultra Wide Band, (WCS) Wireless communication systems.

Posted Date: May 13th, 2021

DOl: https://doi.org/10.21203/rs.3.rs-482848/v1

License: (c) (1) This work is licensed under a Creative Commons Attribution 4.0 International License. Read Full License 


\title{
Microstrip antenna analysis with aid of ultra wide band
}

\section{applications}

\author{
$1 *$ N. Parthiban, ${ }^{2}$ Dr. M. Mohamed Ismail \\ 1*Department of Electronics and Communications Engineering, B. S. Abdur Rahman \\ Crescent Institute of Science \& Technology, Chennai, India. \\ parthibannece@gmail.com
${ }^{2}$ Department of Electronics and Communications Engineering, B. S. Abdur Rahman Crescent Institute of Science \& Technology, Chennai, India.
mohamedismailmece@gmail.com

\begin{abstract}
Microstrip antenna is an essential choice for Ultra Wide Band (UWB) applications of its light weight, low profile and easy to form antenna arrays. However, the design of microstrip patch antenna bandwidth is greatly affects by the dielectric substrate material (FR4). In this research, the bandwidth enhancement of MPA was designed by minimizing the dimension of Defected GP (DGP) in GP for Ultra Wide Band wireless applications. But, the antenna design complexity increases with the number of an operating frequency band. In this research, the MPA was designed as small as size of $10 \times 13 \times 1.6 \mathrm{~mm}$ and operates on frequency band between $3.1 \mathrm{GHz}$ to $10.6 \mathrm{GHz}$ for VSWR less than 2. The microstrip patch antenna was designed at $3.1 \mathrm{GHz}$ to $10.6 \mathrm{GHz}$ using High-Frequency Structure Simulator (HFSS) software. The simulation result shows that the proposed microstrip patch antenna obtained $<-10 \mathrm{~dB}$ of return loss from $3.1 \mathrm{GHz}$ to $10.6 \mathrm{GHz}$ throughout the frequency range. The measured result proves that the proposed microstrip patch antenna has better characteristics to fulfill the requirements of UWB applications.
\end{abstract}


Keywords: Bandwidth; Ground Plane (GP); Microstrip patch antenna (MPA); Operating frequency; Spectrum; and Ultra Wide Band; (WCS) Wireless communication systems.

\section{Introduction}

Recently, the WCS require high quality, cost-effective and Miniaturized Antenna Devices (MAD) with enhanced features because of an increase in data rates and trend of miniature electronics circuits. The MPA is widely used for WCS because of their lightweight, low profile and cost-effective [1]. The MPA contains a radiating patch on one of a dielectric substrate, which has a GP on another side. Generally, the microstrip patch is made of conducting material like copper and it can take any effective possible shape. The radiating microstrip patch and the feed lines are usually photo etched on the dielectric substrate. [2]. The design of microstrip antennas has benefited from the unrelenting growth in computational power and the increased availability of accurate and efficient methods to numerically solve Maxwell's equations [3]. The microstrip patch antennas suffer from a number of limitations as patch length is around half a wavelength [4]. The performance of the microstrip antenna can be developed in terms of gain, matching performance, impedance bandwidth, and return loss by presenting a defect in the GP [5]. F The DGS is either nonperiodic or fixed periodic cascade configuration defect in GP and any type of defect in the GP can give rise to increase in effective inductance and capacitance [6]-[7].

The GP is one of the important parts of a microstrip patch antenna, since it affects several of the antenna's characteristics. Therefore, it is necessary for an antenna designer to understand the effects of the GP on antenna characteristics in order to be able to select a GP size suitable for the particular application [8]. Numerous approaches have been utilized to achieve compact microstrip antenna (for example high dielectric constant substrate, adopting 
short-circuit pin, and slots loaded on the patch) [9]. The traditional antenna design scheme requires a complex structure and feeding technique like more layers and parasitic structures. To overcome the complexity of antenna structure, this research the bandwidth enhancement of MLF is designed by minimizing the length of DGP in GP for UWB wireless applications. The major aim of the proposed microstrip patch antenna is obtaining wide broad bandwidth with high radiation efficiency and decrease the size of GP structure. Several factors must be taken into account including impedance, physical profile, bandwidth, radiation efficiency, radiation pattern, return loss, and VSWR to select optimized antenna topology for UWB applications by using HFSS software.

This research paper is composed as follows, Section 2 presents an extensive survey of recent papers on GP structure reduction techniques for microstrip antennas. Section 3 briefly described the proposed microstrip patch antenna design. Section 4 presents the experimental result of proposed microstrip antenna and the obtained results are compared with existing antenna designs. The conclusion is made in Section 5.

\section{Literature Survey}

The researchers have suggested a number of GP structure reduction techniques for microstrip antennas. Brief evaluations of a few significant size reduction techniques for microstrip antenna are presented in this section.

Jain and Shubhi [10] designed Planar Microstrip Patch Antenna (PMPA) with a full GP, which is suitable to operate at $5.5 \mathrm{GHz}$ frequency with $200 \mathrm{MHz}$ bands. The return loss at $5.5 \mathrm{GHz}$ is $-29.5 \mathrm{~dB}$ for inset feed antenna. The maximum gain was $5.7 \mathrm{~dB}$ and bandwidth was $200 \mathrm{MHz}$ for entire ground and $210 \mathrm{MHz}$ for the defected GP antenna. This proposed antenna used for the Wireless Land Area Network (WLAN) applications. The return loss of - 
$36.81 \mathrm{~dB}$ was improved after introducing a pyramidal shape defected GP at the same frequency. The width of the patch and length is high in the proposed method.

Pandhare et al. [11] proposed work was obtained a miniaturized Microstrip Patch Antenna Array (MPAA) utilizing DGS for S-band at 2.2 GHz. First, the patch antenna array was designed at C-band resonates at $5.2 \mathrm{GHz}$ of frequency. The Proposed DGS was integrated into GP of patch antenna array used for size reduction. In this work, the proposed DGS was integrated in the GP of the patch antenna array for antenna size reduction. By using this way, to enhance the gain of proposed miniaturization radiator and the patch radiator was modified to retain its properties of radiations. At the final stage, the resonance frequency of original MPAA shifts from $5.2 \mathrm{GHz}$ to $2.2 \mathrm{GHz}$ and with good performance reduction up to $83 \%$. The proposed method is obtained - $16 \mathrm{~dB} \mathrm{~S}$-parameter, it is not sufficient for effective antenna applications.

Matekovits et al. [12] proposed a mutual coupling reduction between Implanted Microstrip Antennas (IMAs) on cylindrical bimetallic GP. In this work cylindrical bio-metal implant serves as the common ground plane for the conformal antennas. This cylindrical bio metal serves as the common GP for conformal antennas. Then the mutual coupling between two- conformal microstrip antennas was studied and quantified for various spacing between the antennas. Three methods were proposed such as top method, middle method and bottom method to minimize mutual coupling between two - antennas. But, maximum coupling reduction is $7 \mathrm{~dB}$ at 75 degree for small angles and the mutual coupling reduction is not significant.

Wei et al. [13] proposed S-shaped periodic DGS to reduce mutual coupling between the antenna elements. This proposed PDGS method significantly disturbs the fields and induces currents in microstrip antenna elements to reduce mutual coupling. The periodic DGS method obtained more than $40 \mathrm{~dB}$ mutual coupling reduction in microstrip antenna 
elements. Furthermore, there is no much significant variance between the simulated and measured Main Lobe Patterns (MLP) in upper sphere space. But, the size of the proposed antenna is more complex.

Painam, Surendrakumar, and Chandramohan Bhuma [14] proposed a size reduction technique when a circular microstrip patch was loaded with a meta-material structure. This technique utilized a complementary split ring resonator with partially loaded Non-Uniform Meta Surface (NUMSs) on the GP for obtaining better performance. The proposed antenna resonating at $6.22 \mathrm{GHz}$ was designed, fabricated, tested and measured. The proposed antenna was obtained $74 \%$ of size reduction compared to traditional microstrip antenna. The proposed antenna can be utilized for wireless applications like indoor base station antenna for vehicle-to-vehicle communications. The substrate dimension is high $23 \times 24 \times 0.51$ of antenna.

\section{Antenna Design and Performances}

The proposed microstrip patch antenna design consists of a monopole antenna with a microstrip feed line and the GP. The proposed antenna design is used to attain multiband just through placing the reduced dimensions of DGS in GP, so it much easier to fabricate. In this research, the proposed microstrip slot antenna is developed for UWB applications. The UWB technology has regarded as wide technologies in the wireless world due to their efficient features. 


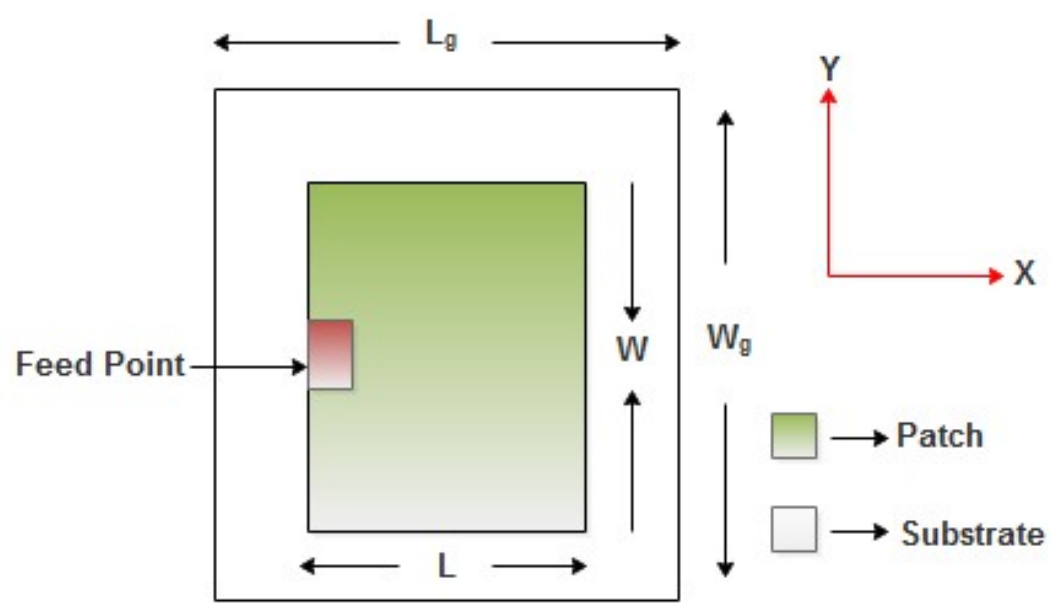

Figure. 1 Proposed microstrip antenna design

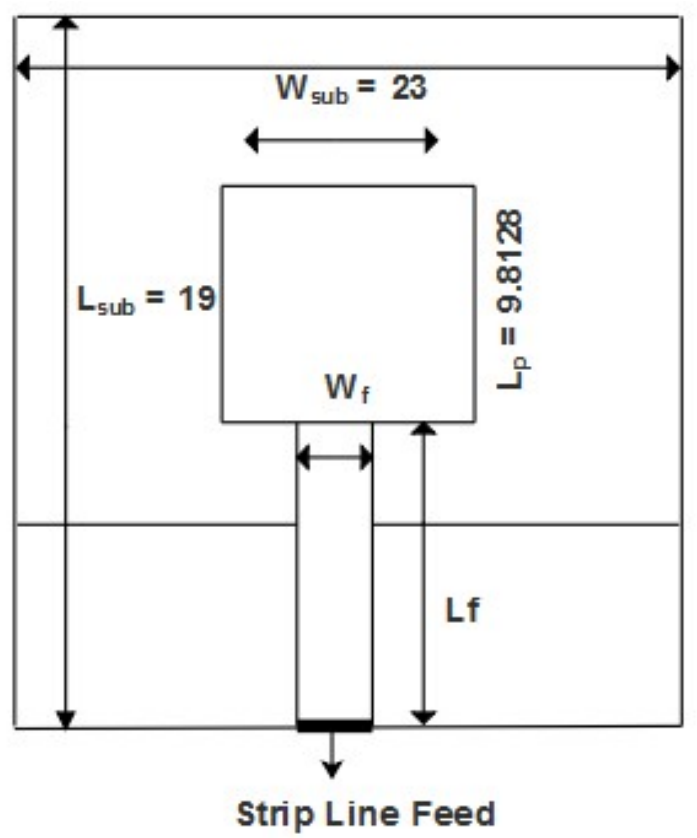

Figure. 2 Geometry of the front view for the proposed microstrip antenna

The proposed microstrip patch antenna is shown in fig. 1. Fig. 2 depicts geometry of the front view for the proposed microstrip antenna at the edge of the patch. In this research, width and the length of the patch will be affecting the performance of the patch antenna. Hence some important parameter such as bandwidth, impedance, return loss, and VSWR are computed by the formulas to achieve a compact structure of the microstrip antenna. The 
proposed microstrip patch antenna consists of substrate, GP and patches. The size of the proposed antenna is $13 \times 10 \times 1.6 \mathrm{~mm}$.

\subsection{Design of microstrip antenna at 6. $85 \mathrm{GHz}$}

The configuration of the simulated microstrip antenna is designed and fabricated on a substrate with FR4_epoxy, the relative permittivity of 4.4, and a loss tangent of 0.02 . In this proposed antenna design, the entire size of the antenna is only $10 \times 13 \times 1.6 \mathrm{~mm}$. The microstrip antenna should be operated in $3.1 \mathrm{GHz}$ to $10.6 \mathrm{GHz}$ of the frequency range. So, the width of the patch is chosen from eq. (1). By using these computations, the dimensions of the antenna are concluded in Tab .1. The simulation results of the fabricated microstrip antenna is shown fig $3 \& 4$

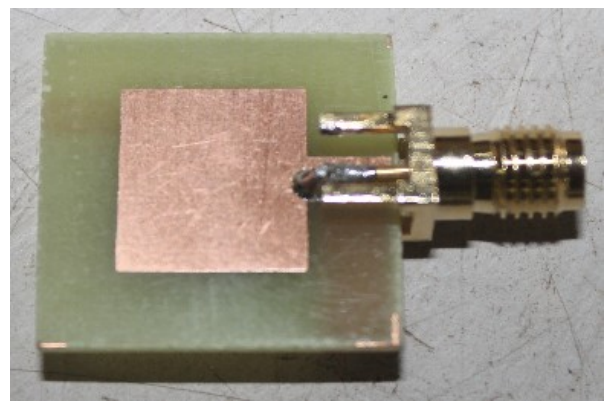

Figure. 3 Photography of top view fabricated microstrip antenna

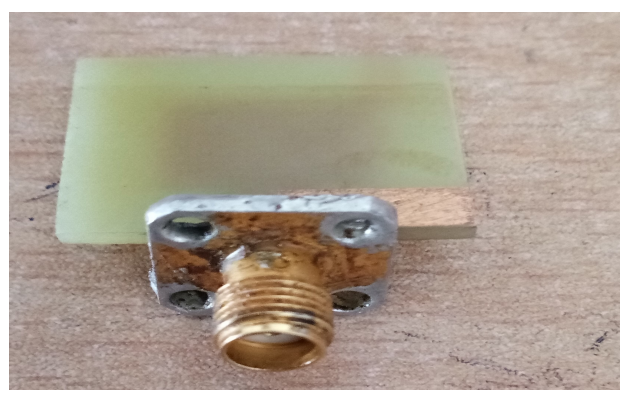

Figure. 4 Photography of back view fabricated microstrip antenna

From the numerical computational methods, the simulation studies and exhaustive experimental following design equation are derived for reduced the GP structure, which allows to compute the length of a patch at $6.85 \mathrm{GHz}$ of operating frequency. The width of patch is computed by eq. (1). 


\subsubsection{Computation of the width of patch}

The width is critical in impedance and power efficiency, it depends upon the operating frequency and height of the substrate.

$$
W=\frac{c}{2 f_{0}} \sqrt{\frac{2}{s_{r}+1}}
$$

Here, $c$ is speed of light $\left(3 \times 10^{8} \mathrm{~m} / \mathrm{s}\right), \varepsilon_{r}$ is permittivity of substrate (4.4), $f_{0}$ is resonance frequency $(6.85 \mathrm{GHz})$. By using equation (1) the width of patch is $13.33 \mathrm{~mm}$.

\subsubsection{Calculation of effective dielectric constant}

Effective dielectric constant is minimum than dielectric constant due to fringing field around the margin of the patch.

$$
\varepsilon_{\text {eff }}=\frac{\varepsilon_{r}+1}{2}+\frac{\varepsilon_{T}-1}{2}\left[1+12 \frac{h}{w}\right]^{-\frac{1}{2}}
$$

Here, $h$ is the height of substrate $(1.6 \mathrm{~mm}), w$ is width of the patch $(13.33 \mathrm{~mm})$ and $\varepsilon_{r}$ is 4.4. By using equation (2) the effective dielectric constant value is 3.788 .

\subsubsection{Calculation of effective length}

The transmission line method is applicable to infinite GP. However, it is important to have a finite GP for practical consideration. The calculation of effective length has been exposed by the similar result for infinite and finite GP. The effective of the length is expressed in equation (3).

$$
L_{e f f}=\frac{e}{2 f_{0 \sqrt{E_{e f f}}}}
$$

Here, $\varepsilon_{\text {eff }}$ is $3.788, c$ is $3 \times 10^{8} \mathrm{~m} / \mathrm{s}$ and $f_{0}$ is $6.85 \mathrm{GHz}$. The effective length is 11.25 .

\subsubsection{Calculation of length extension and length of patch}

The practical approximations used for length extension $(\Delta L)$ is expressed by using equation (4). 


$$
\Delta L=0.412 \times h \frac{\left(s_{\text {eff }}+0.3\right) \times\left(\frac{w}{h}+0.264\right)}{\left(s_{\text {eff }}-0.258\right) \times\left(\frac{w}{h}+0.264\right)}
$$

Here, $w$ is $13.33 \mathrm{~mm}, h$ is $1.6 \mathrm{~mm}$ and $\varepsilon_{\text {eff }}$ is 3.788 . The length of extension is 0.843 .

The actual length of the patch is expressed by equation (5).

$$
L=L_{\text {eff }}-2 \Delta L
$$

Here, $L_{\text {eff }}$ is $11.25 \mathrm{~mm}$ and $\Delta L$ is 0.843 . The actual length of the patch is 9.564 .

\subsubsection{Calculation of GP dimension}

The calculation of GP dimension is obtained by using equation (6) and (7).

$$
\begin{aligned}
& L_{\text {ground }}=6 h+L=6(1.6)+9.8128=19.413 \mathrm{~mm} \\
& W_{\text {ground }}=6 h+L=6(1.6)+13.33=22.93 \mathrm{~mm}
\end{aligned}
$$

Several number of feeding methods are presented for microstrip patch antenna, from these, the strip line feed is chosen for this proposed microstrip antenna to obtain the better matching impedance of $50 \Omega$. By using equations (8) and (9) the feeding points are chosen.

$$
\begin{aligned}
& X_{f}=\frac{L}{2} \sqrt{\varepsilon_{\text {off }}} \\
& Y_{f}=\frac{\text { Width of the patch }}{2}
\end{aligned}
$$

The rectangular shape is most commonly employed configuration for the patch antenna due to easy to analysis employing transmission line. This proposed MPA-DGP-UWB antenna is realized by etching rectangular slots in GP of the antenna and allows to obtain the desired frequency bands with better performance.

\subsection{Design of the Microstrip Antenna Using HFSS for FR4}

The performance of the proposed microstrip patch antenna is analyzed by HFSS software. The design of the antenna follows four types of the setup such as planar EM design, model, excitation and analysis. By utilizing this HFSS software, this research will compute 
the gain, VSWR, return loss with no error. The proposed antenna design obtained appropriate results using this software when compared with other software.

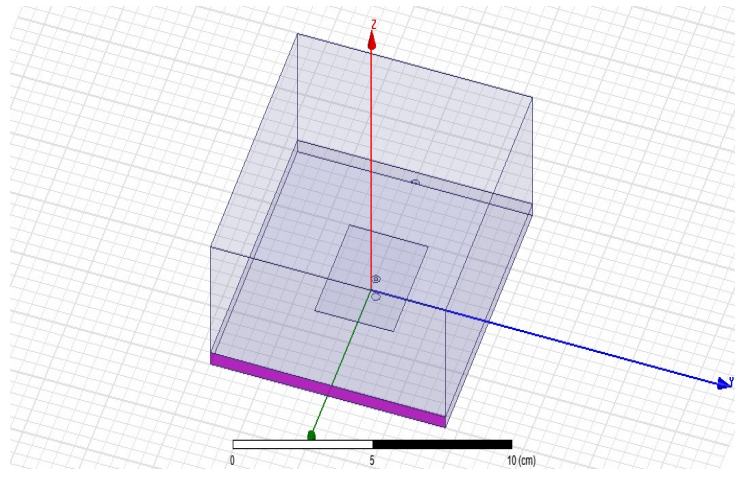

Figure. 5 Design of microstrip antenna in the excitation setup

Creation of infinite conductivity is involved in this proposed microstrip antenna. The position values are evaluated by using the formulas for width, length. In this research, the material for the substrate is taken as Fr4_epoxy which has dielectric constant as 4.4. Fig. 5 shows the design of microstrip antenna in the excitation setup. In excitation setup, draw the lumped port from the assign boundaries window and also create radiation box around the antenna for radiation. The radiation box also has some positions which can be computed. The directivity and the impedance matching can be calculated in this analysis setup. In this analysis setup, return loss, VSWR, and input impedance of proposed microstrip patch antenna are calculated. This can be created by analyzing in far-field report and rectangular plot. Fig. 6 shows the designed microstrip antenna.

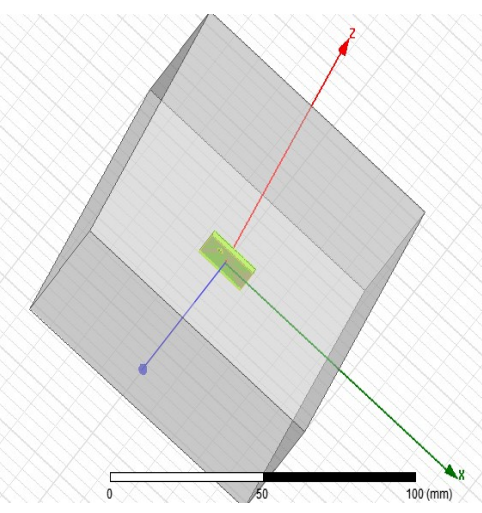

Figure. 6 Designed microstrip antenna 


\section{Results and discussion}

The accomplishment of the prototype of the investigated antenna allows to analyse the performance of the structure and to validate the results are achieved from a simulation. In this research, the DGS antenna is fabricated by utilizing photolithographic approach and chemical etching process by undesirable metal areas of the metallic layer are removed, so that intended design is obtained. Furthermore, the return loss is analysed by Vector Network Analyzer (VNA) PNA-X from Agilent technologies. Here, 50 ohms used for matched impedance with a characteristic impedance. The final reduction dimensions of the microstrip antenna is represented in Table 1.

Table.1 Dimension of the proposed microstrip slot antenna

\begin{tabular}{|c|c|}
\hline Parameter & Dimensions (mm) \\
\hline$W_{p}$ & 13.33 \\
\hline$L_{p}$ & 9.8128 \\
\hline$W_{\text {sub }}$ & 23 \\
\hline$L_{\text {sub }}$ & 19 \\
\hline$W_{\text {ground }}$ & 22.93 \\
\hline$L_{\text {ground }}$ & 19.413 \\
\hline$h$ & 1.6 \\
\hline
\end{tabular}

In this scenario, the simulation and analysis are done for the MPA-DGP-UWB antenna and designed by HFSS simulator.

\subsection{Performance Metrics}

The performance measures which were obtained from this simulation are given as follows: 


\subsubsection{Return loss $(d B)$}

It is loss of the power in the signal reflected by a discontinuity in a transmission line. The return loss $(\mathrm{dB})$ is expressed by equation (10).

$$
\text { Return Loss }(d B)=10 \log _{10} \frac{p_{i}}{p_{r}}
$$

Here, $P_{i}$ is the incident power and $P_{r}$ is the reflected power. The return loss is related to both reflection coefficient and Standing Wave Ration (SWR).

\subsubsection{VSWR}

The VSWR is the sum of mismatch between antennas and the feeding line. It is calculated for knowing the amount of reflected power and the mathematical expression for VSWR is given in equation (11).

$$
V S W R=\frac{1+|\Gamma|]}{1-|\Gamma|}
$$

Here, $\Gamma$ is the Reflection Coefficient (RC).

\subsection{Simulation and fabricated results}

Figs. 7 and 8 shows the schematic diagram of GP length and return loss plot, it is evident that the antenna provided better bandwidth, and double of bandwidth compared to other existing antennas. The performance VSWR is examined for microstrip antenna and the corresponding plot for the same was obtained. From the simulation result, the VSWR $(<2 \mathrm{db})$ is obtained from 9.3Ghz-9.7Ghz frequency range. Figs. 9 shows VSWR performance for GP length of $4 \mathrm{~mm}$ and GP width of $11 \mathrm{~mm}$. 


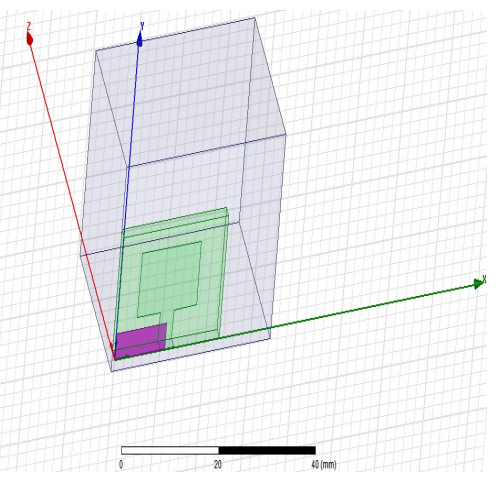

Figure. 7 Schematic diagram of iteration for GP length is $4 \mathrm{~mm}$ and GP width is $11 \mathrm{~mm}$

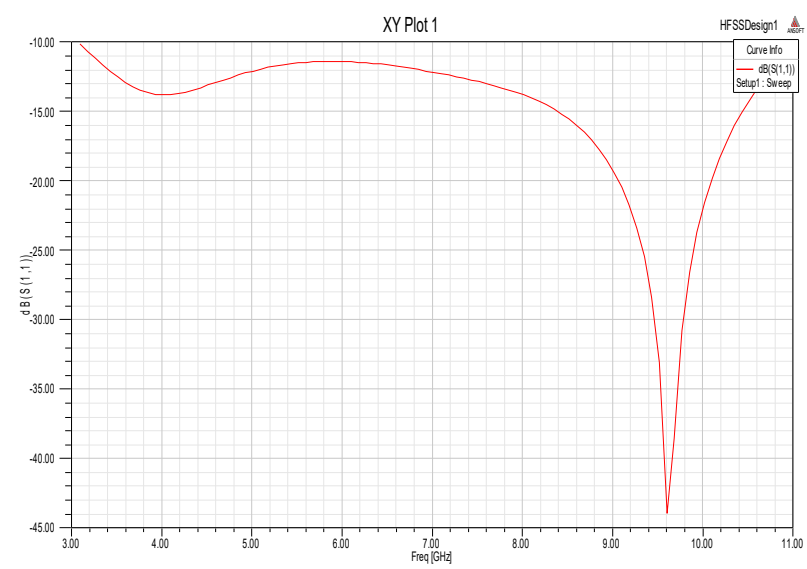

Figure. 8 Return Loss Plot for GP length is $4 \mathrm{~mm}$ and the GP width is $11 \mathrm{~mm}$

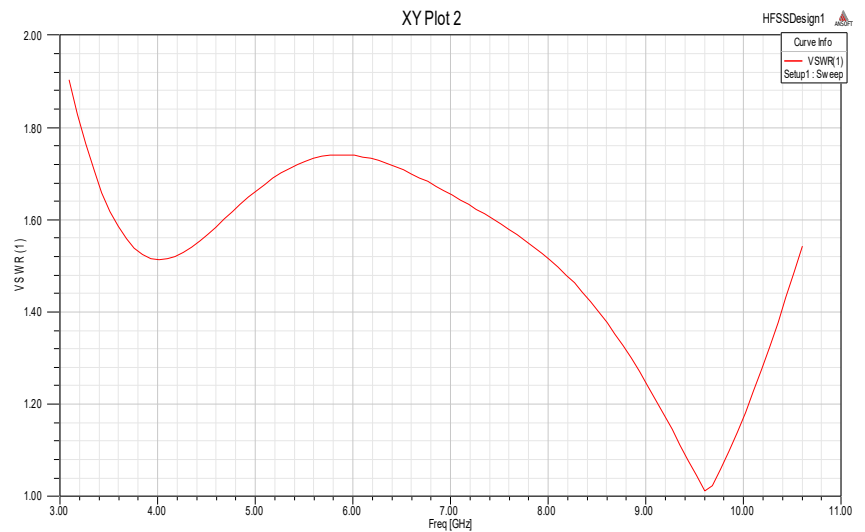

Figure. 9 VSWR Plot for GP length is $4 \mathrm{~mm}$ and the GP width is $11 \mathrm{~mm}$

Table.2 shows the iteration of UWB microstrip antenna design using FR4. In the table.2, the number of iteration is 17 . There are different parameter dimensions are available such as GP width, GP width, dielectric substrate width, dielectric substrate length, dielectric substrate hight, patch length, patch width, Radiation box width, Radiation box length, and 
Radiation box hight. The manuscript antenna was obtained better results in the $16^{\text {th }}$ iteration.

Table. 3 shows the Iteration of UWB microstrip antenna design using FR4. The VSWR and return loss are analysed for 17 iteration. Although the better VSWR and return loss obtained in $16^{\text {th }}$ iteration.

Table. 2 Iteration of UWB microstrip antenna design using FR4

\begin{tabular}{|c|l|l|l|l|l|l|l|l|l|l|l|l|l|l|l|l|l|}
\hline $\begin{array}{c}\text { Parameter Dimension } \\
(\mathrm{mm})\end{array}$ & \multicolumn{10}{|c|}{ Number of Iterations } \\
\cline { 2 - 6 } & $\mathbf{1}$ & $\mathbf{2}$ & $\mathbf{3}$ & $\mathbf{4}$ & $\mathbf{5}$ & $\mathbf{6}$ & $\mathbf{7}$ & $\mathbf{8}$ & $\mathbf{9}$ & $\mathbf{1 0}$ & $\mathbf{1 1}$ & $\mathbf{1 2}$ & $\mathbf{1 3}$ & $\mathbf{1 4}$ & $\mathbf{1 5}$ & $\mathbf{1 6}$ & $\mathbf{1 7}$ \\
\hline GP width & 23 & 23 & 20 & 20 & $\mathbf{2 0}$ & 20 & 20 & 20 & 20 & 15 & 18 & 23 & 20 & 15 & 13 & 11 & 10 \\
\hline GP length & 15 & 10 & 8 & 7 & 12 & 14 & 13 & 11 & 11 & 11 & 11 & 11 & 5 & 4 & 4 & 4 & 4 \\
\hline Dielectric substrate width & 23 & 23 & 23 & 23 & 23 & 23 & 23 & 23 & 23 & 23 & 23 & 23 & 23 & 23 & 23 & 23 & 23 \\
\hline Dielectric substrate length & 19 & 19 & 19 & 19 & 19 & 19 & 19 & 19 & 19 & 19 & 19 & 19 & 19 & 19 & 19 & 19 & 19 \\
\hline Dielectric substrate hight & 1.6 & 1.6 & 1.6 & 1.6 & 1.6 & 1.6 & 1.6 & 1.6 & 1.6 & 1.6 & 1.6 & 1.6 & 1.6 & 1.6 & 1.6 & 1.6 & 1.6 \\
\hline Patch width & 13 & 13 & 13 & 13 & 13 & 13 & 13 & 13 & 13 & 13 & 13 & 13 & 13 & 13 & 13 & 13 & 13 \\
\hline Patch length & 10 & 10 & 10 & 10 & 10 & 10 & 10 & 10 & 10 & 10 & 10 & 10 & 10 & 10 & 10 & 10 & 10 \\
\hline Radiation box width & 35 & 35 & 35 & 35 & 35 & 35 & 35 & 35 & 35 & 35 & 35 & 35 & 35 & 35 & 35 & 35 & 35 \\
\hline Radiation box length & 32 & 32 & 32 & 32 & 32 & 32 & 32 & 32 & 32 & 32 & 32 & 32 & 32 & 32 & 32 & 32 & 32 \\
\hline Radiation box hight & 22 & 22 & 22 & 22 & 22 & 22 & 22 & 22 & 22 & 22 & 22 & 22 & 22 & 22 & 22 & 22 & 22 \\
\hline
\end{tabular}

Table. 3 Iteration of UWB microstrip antenna design using FR4

\begin{tabular}{|c|c|c|c|c|c|c|c|c|c|c|c|c|c|c|c|c|c|}
\hline $\begin{array}{c}\text { Parameter } \\
\text { (GHz) }\end{array}$ & \multicolumn{17}{|c|}{ Number of Iterations } \\
\hline $\begin{array}{l}\text { VSWR } \\
(<2)\end{array}$ & $10-10.1$ & $\begin{array}{l}9.3- \\
9.6\end{array}$ & $\begin{array}{l}8.6- \\
10.6\end{array}$ & $\begin{array}{l}10.2- \\
10.6\end{array}$ & $\begin{array}{l}10.2- \\
10.6\end{array}$ & $\begin{array}{c}7.2- \\
7.5 \& \\
9.4- \\
10\end{array}$ & $\begin{array}{l}9.5- \\
7.5\end{array}$ & $\begin{array}{c}9.5- \\
9.8\end{array}$ & $\begin{array}{l}7.8- \\
8.9\end{array}$ & $\begin{array}{c}8- \\
10.6\end{array}$ & $\begin{array}{c}7.9- \\
8.8 \& \\
9.7- \\
10.6\end{array}$ & $\begin{array}{l}7.6- \\
8.5 \& \\
9.6- \\
10.6\end{array}$ & $\begin{array}{l}9.4- \\
10.6\end{array}$ & $\begin{array}{c}4- \\
10.6\end{array}$ & $\begin{array}{l}3.5- \\
10.6\end{array}$ & $\begin{array}{l}3.1- \\
10.6\end{array}$ & $3.9-9$ \\
\hline
\end{tabular}


Figure. 10 shows the simulated return loss for proposed microstrip slot antenna based on iterations. It indicates the return loss value $<-10 \mathrm{~dB}$ for the frequency range 3.1 to 10.6 GHz. Further, it proves an increasing value of the return loss from $10.6 \mathrm{GHz}$ onwards. The return loss values for different frequencies $3.1 \mathrm{GHz}, 4 \mathrm{GHz}, 6 \mathrm{GHz}, 8 \mathrm{GHz}, 10 \mathrm{GHz}$ are -10 $\mathrm{dB},-20.6 \mathrm{~dB},-20.4 \mathrm{~dB},-20.1 \mathrm{~dB},-35 \mathrm{~dB}$. From this obtained results the proposed microstrip slot antenna shows better-simulated return loss about $-10 \mathrm{~dB}$. Fig. 11 shows the VSWR value lesser than 2 for the frequency range of 3.1 to $10.6 \mathrm{GHz}$. At the frequency range $3.1 \mathrm{GHz}$, the VSWR value is 38 . After that, the VSWR values are further decreasing to 25,25 , and 10 for $4 \mathrm{GHZ}, 5 \mathrm{GHZ}$ and $6 \mathrm{GHz}$, the corresponding VSWR values are 10, 20, 25 and 38 . Desired VSWR $(<2)$ is obtained in the frequency range of 3.1 to $10.6 \mathrm{GHz}$. It covers the lower and middle range of the UWB antennas. Table. 4 shows the size of antenna analysis of proposed multiscript antenna with conventional antennas.

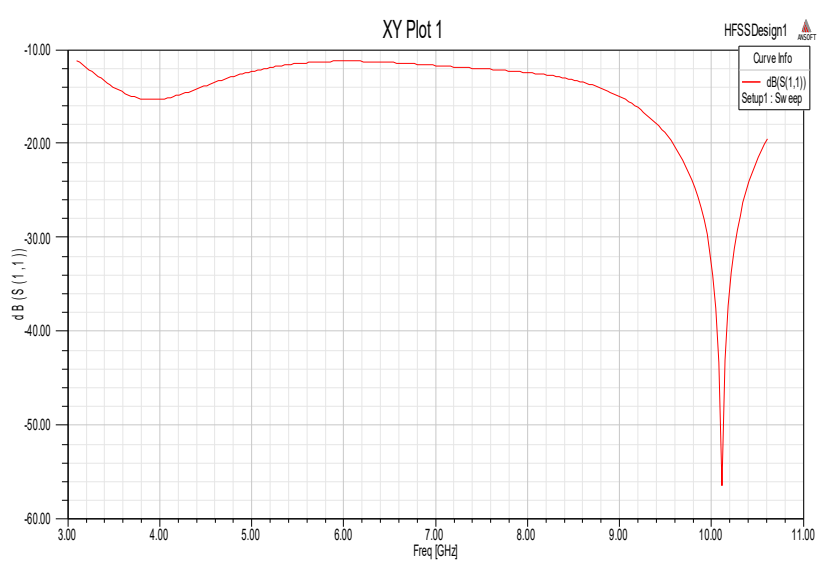

Figure. 10 Simulated graph of return loss 


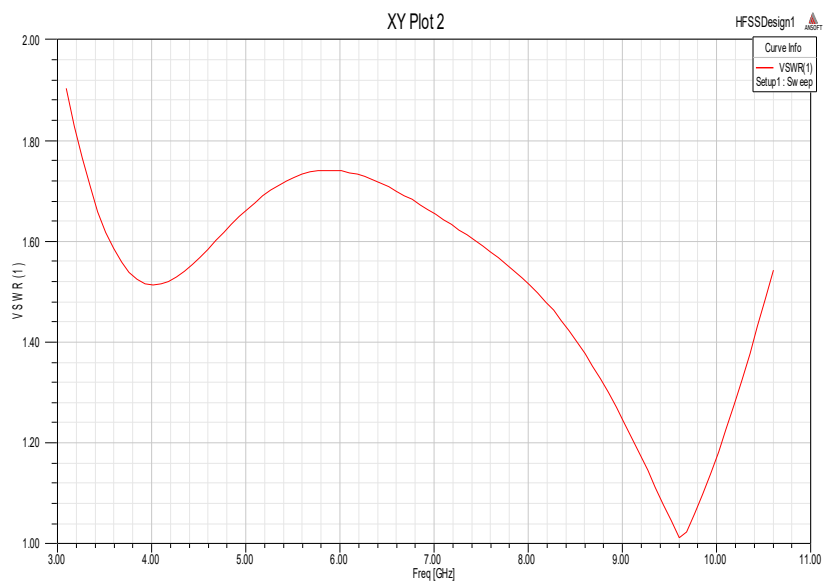

Figure. 11 Simulated graph of VSWR

The simulation results show that the obtained return loss is less than $-10 \mathrm{~dB}$. Approximately, the proposed antenna obtained $-10 \mathrm{~dB}$ in 3.1 to $10.6 \mathrm{GHz}$ in UWB band. Finally, this microstrip antenna attained better return loss, which is utilized in UWB applications. This antenna obtains VSWR less than 2 for each UWB band and $6.85 \mathrm{GHz}$ of operating frequency. Figs. 12 and 13 shows the top and back view of the fabricated antenna's tested diagram. Table. 4 shows the measurement of the fabricated antenna for testing with the different frequency range.

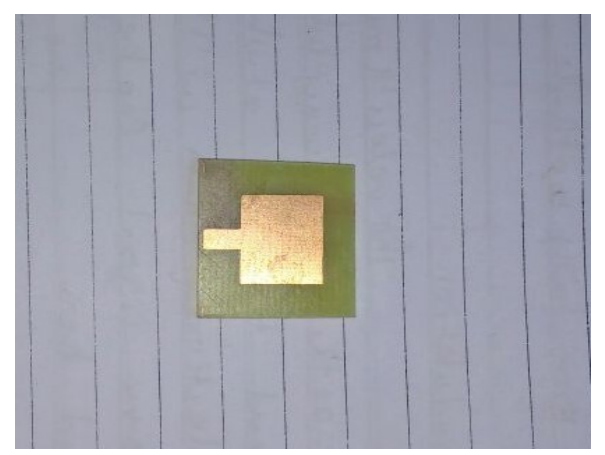

Figure. 12 Fabricated prototype of antenna top view 


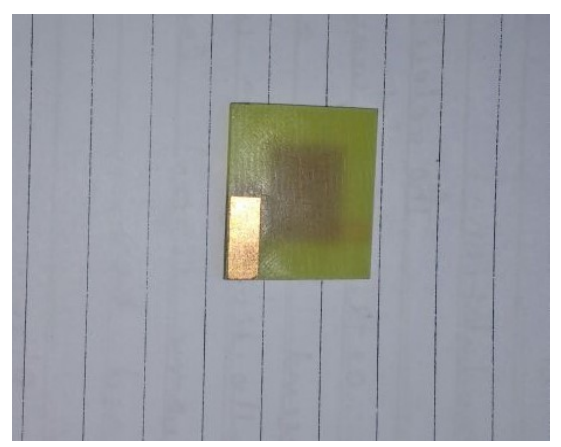

Figure. 13 Fabricated prototype of antenna back view

Table. 4 Measurement of Fabricated antenna for testing

\begin{tabular}{|c|c|}
\hline Frequency (GHz) & Return Loss (dB) \\
\hline 3.6 & -9.06 \\
\hline 4 & -10.1 \\
\hline 4.5 & -10.6 \\
\hline 5 & -10.12 \\
\hline 5.5 & -10.28 \\
\hline 6 & -10.42 \\
\hline 6.5 & -10.67 \\
\hline 7 & -10.97 \\
\hline 7.5 & -10.84 \\
\hline 8 & -10.26 \\
\hline 8.5 & -10.6 \\
\hline 9 & -10.7 \\
\hline 9.5 & -10.16 \\
\hline 10 & -10.13 \\
\hline 10.5 & -10.1 \\
\hline
\end{tabular}


The main intention of using DGS is to satisfy the return loss of $-10 \mathrm{GHz}$. The return loss of the original microstrip antenna was enhanced significantly from $3.1 \mathrm{GHz}$ to $10.6 \mathrm{GHz}$ with DGS (Table 5). After optimization process, the size of original microstrip antenna has reduced compared to the existing microstrip antenna size.

Table. 5 Size analysis of proposed multiscript antenna with conventional antennas

\begin{tabular}{|l|c|c|c|c|}
\hline \multicolumn{1}{|c|}{ Author } & Antenna Size mm & $\begin{array}{c}\text { Frequency } \\
\text { (GHz) }\end{array}$ & $\begin{array}{c}\text { Return Loss } \\
(\mathbf{d B})\end{array}$ & VSWR \\
\hline Pandhare [14] & $23 \times 24 \times 0.51$ & 6.22 & 39.53 & - \\
\hline Tiwari et al. [15] & $25 \times 17 \times 1.6$ & 2.94 & 5 & $\leq 2$ \\
\hline \multirow{2}{*}{ Sharma, Narinder, } & $45 \times 38.92 \times 1.6$ & $2.41 \& 8.34$ & $-14.86 \&-15.76$ & $1.44 \&$ \\
and Vipul Sharma & $45 \times 38.92 \times 1.6$ & $2.68 \& 8.38$ & $-14.26 \& 16.11$ & 1.48 \\
\cline { 2 - 5 } [16] & & & & \\
\hline Proposed microstrip & $10 \times 13 \times 1.6$ & 3.1 to 10.6 & -10 & $<2$ \\
\hline antenna & & & & \\
\hline
\end{tabular}

\subsection{Network Analyzer}

The VNA is a one of the efficient network computing tool that can be utilized to compute the input impedance as a frequency function. Otherwise, it can plot both S11 (return loss) and VSWR based on frequency-dependent function of the antenna impedance. The VNA is shown fig. 13. 


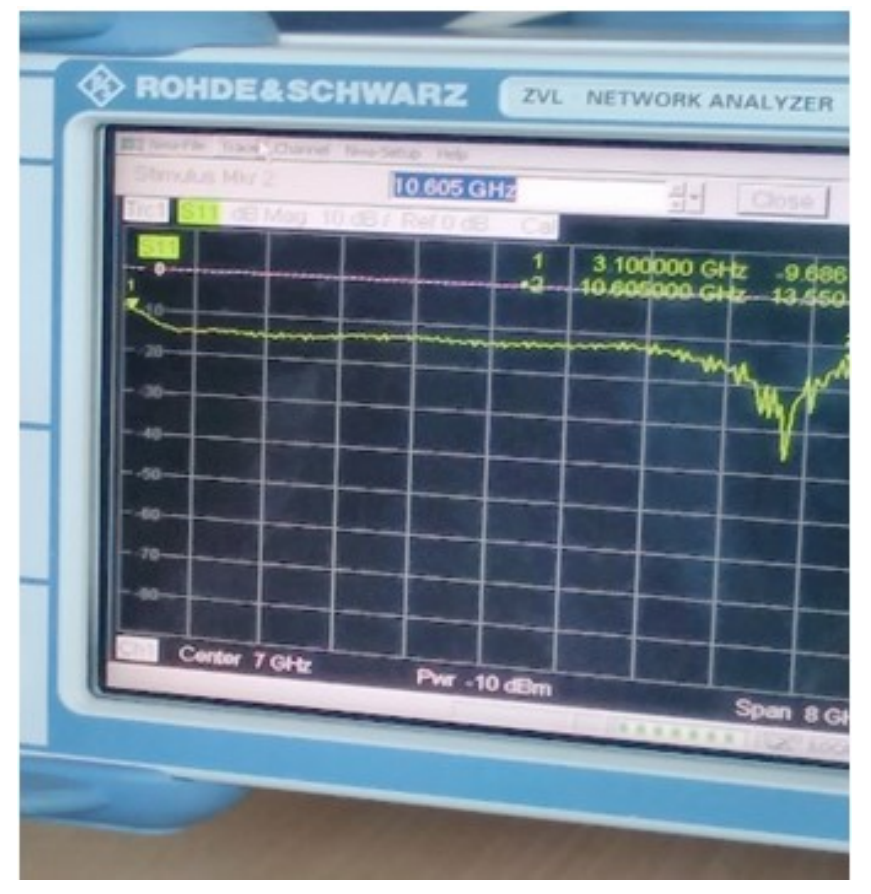

Figure. 13 Vector Network Analyzer

The VNA transfers a very small quantity of power to the proposed antenna and the reflected power is calculated by using VNA Tool. The $\mathrm{S}$ - parameter is the fundamental magnitude of reflection coefficient, it depends on antenna impedance and impedance of VNA that is typically $50 \Omega$. The points above the equator of the Smith chart denotes an inductive impedance with a positive reactance. As well as points under the equator of the Smith chart denote capacitive impedance with a negative reactance. The Smith chart is an effective tool of viewing impedance over a frequency range in a concise, and clear form.

\section{Comparison between reported and proposed UWB Antennas:}

Here, this table shows the comparison of the reported and proposed UWB antennas. It is showing the proposed antenna have comparatively achieved 3.1 to $10.6 \mathrm{GHz}$ throughout the band.

Table. 6 Comparison between reported and proposed UWB Antennas

\begin{tabular}{|l|l|l|l|l|l|l|}
\hline S. & Title \& Ref No. & Shape & Size & Material & Thickness & Operating \\
No & & $\left(\mathrm{mm}^{2}\right)$ & & Frequency \\
\hline
\end{tabular}




\begin{tabular}{|c|c|c|c|c|c|c|}
\hline & & & & & & $(\mathrm{GHz})$ \\
\hline 1. & $\begin{array}{l}\text { Bandwidth Improvement of } \\
\text { UWB Microstrip Antenna } \\
\text { Using Finite Ground Plane } \\
{[17]}\end{array}$ & $\begin{array}{c}\text { Rectangle } \\
\text { Patch }\end{array}$ & $12 \times 16$ & FR-4 & 1.6 & 6.5 to 13.7 \\
\hline 2. & $\begin{array}{l}\text { Microstrip Antenna Design } \\
\text { for UWB Applications [18] }\end{array}$ & $\begin{array}{l}\text { Circular } \\
\text { Patch }\end{array}$ & $31.17 \times 40$ & FR-4 & 0.787 & 2.7 to 8.2 \\
\hline 3. & $\begin{array}{l}\text { Novel Microstrip Antenna } \\
\text { Aims at UWB Applications } \\
{[19]}\end{array}$ & $\begin{array}{c}\text { Rectangle } \\
\text { Patch }\end{array}$ & $20 \times 15$ & $\begin{array}{l}\text { Rogers } \\
\text { RO4003 }\end{array}$ & 0.813 & 2.65 to 10 \\
\hline 4 & $\begin{array}{l}\text { Design and construction of } \\
\text { microstrip UWB antenna } \\
\text { with time domain analysis } \\
{[20]}\end{array}$ & $\begin{array}{c}\text { Rectangle } \\
\text { Patch }\end{array}$ & $18 \times 11$ & FR-4 & 1.6 & 4.1 to 10 \\
\hline 5. & Proposed Antenna & $\begin{array}{c}\text { Rectangle } \\
\text { Patch }\end{array}$ & $10 \times 13$ & $F R-4$ & 1.6 & 3.1 to 10.6 \\
\hline
\end{tabular}

\section{Conclusion}

In this research, a compact multiband and miniature microstrip antenna for UWB application is presented. This proposed antenna is designed based on a simple DGS through etching slots on GP, so it can be much easier to fabricate. The measured results shows that the obtained return loss is $-10 \mathrm{~dB}$ and VSWR is lesser than 2 at $3.1-10.6 \mathrm{GHz}$ for better multiband band UWB applications. The features of the proposed microstrip slot antenna have been analyzed through various parametric studies using HFSS simulation software. The 
proposed antenna design can be utilized for UWB applications in the frequency range 3.1 $\mathrm{GHz}$ to $10.6 \mathrm{GHz}$, which is covering the bandwidth of lower and middle-frequency bands. The simulation results prove that the obtained return loss, VSWR and bandwidth is better for UWB applications for using FR4. In future work, the slot-line is considered in the microstrip design for band rejection or band enhancement to reduce the antenna size.

\section{References}

[1] R.A. Pandhare, P.L. Zade and M.P. Abegaonkar, "COMPACT MICROSTRIP PATCH ANTENNA ARRAY WITH DEFECTED GROUND STRUCTURE FOR WIMAX AND UAV APPLICATION", International Journal of Electrical, Electronics and Data Communication, (2015) 3(11)-51-54.

[2] Rahul Tiwari, Dr. Ashish Bagwari, Dr. Vivek Singh Kushwah and Abhishek Senger, ANALYSIS OF A MODIFIED Ground Plane MICROSTRIP PATCH ANTENNA USING CO-AXIAL FEED, International Journal of Engineering Technologies and Management Research, (2018) 5(2):194-200.

[3] Hassan Emadeldeen, Eddie Wadbro and Martin Berggren, "Patch and Ground Plane design of microstrip antennas by material distribution topology optimization", Progress In Electromagnetics Research B, (2014) (59):89-102.

[4] Rashmi A.Pandhare, Prasanna L.Zade and Mahesh P.Abegaonkar, "Miniaturized microstrip antenna array using defected ground structure with enhanced performance", Engineering Science and Technology, an International Journal, (2016) 19(3):1360-1367.

[5] Munish Kumar and Vandana Nath, "Analysis of low mutual coupling compact multi-band microstrip patch antenna and its array using defected ground structure", Engineering Science and Technology, an International Journal, (2016) 19(2):866-874. 
[6] Navya Nanda and Monika Aggarwal, "Analysis and Design of Microstrip Patch Antenna with Defected Ground Structure", International Journal of Engineering Research \& Technology (IJERT, (2014) 3(6):677-680.

[7] Rop. K. V and Konditi. D. B. O., "Performance analysis of a rectangular microstrip patch antenna on different dielectric substrates", Innovative Systems Design and Engineering, (2012) 3(8):7-14.

[8] Raj Kumar, Shinde. J. P and Uplane. M. D, "Effect of Slots in Ground Plane and Patch on Microstrip Antenna Performance", International Journal of Recent Trends in Engineering, (2009) 2(6):34-36.

[9] Soliman A. Shetawy, Esmat A. Abdallah and Darwish Abdel-Aziz, "Slotted ground plane of rectangular patch microstrip antenna with enhanced bandwidth and size reduction", Proceedings of the 12th WSEAS international conference on CommunicationsJuly, (2008) :286-292.

[10] Harpreet Kaur and Monika Aggarwal, "Design of Microstrip Patch Antenna by Introducing Defected Ground Structure", International Journal of Computer Applications, (2015) :0975-8887.

[11] Pallav Rawal and Shubhi Jain, "Performance Improvement of Microstrip Patch Antenna Using Defected Ground Plane", European Journal of Advances in Engineering and Technology, (2015) 2(4):31-33.

[12] Ladislau Matekovits, Jie Huang, Ildiko Peter and Karu P. Esselle, "Mutual Coupling Reduction Between Implanted Microstrip Antennas on a Cylindrical Bio-Metallic Ground Plane", IEEE Access, (2017) 5:8804-8811.

[13] Wei. K, Li. J, Wang. L, Xing. Z and Xu. R, "S-shaped periodic defected ground structures to reduce microstrip antenna array mutual coupling", Electronics Letters, (2016) 52(15):1288-1290. 
[14] Painam. S and Bhuma. C, "Miniaturizing a Microstrip Antenna Using Metamaterials and Metasurfaces [Antenna Applications Corner]", IEEE Antennas and Propagation Magazine, (2019) 61(1):91-135.

[15] Tiwari. R, Singh. P and Kanaujia. B, "A modified microstrip line fed compact UWB antenna for WiMAX/ISM/WLAN and wireless communications", AEU-International Journal of Electronics and Communications, (2019) 104:58-65.

[16] Narinder Sharma and VipulSharma, "A design of Microstrip Patch Antenna using hybrid fractal slot for wideband applications", Ain Shams Engineering Journal, (2018) 9(4):24912497.

[17] Priyanka Mishra and Paras Gupta, "Bandwidth Improvement of UWB Microstrip Antenna Using Finite Ground Plane", International Journal of Engineering Research and Applications, (2015) 5(6):22-25.

[18] Ritu and Krishan Sherdia, "Microstrip Antenna Design for UWB Applications", International Journal of Advanced Research in Computer and Communication Engineering, (2013) 2(10).

[19] Ahmed Boutejdar, Ahmed A. Ibrahim and Edmund P. Burte, "Novel Microstrip Antenna Aims at UWB Applications", Microwaves and RF (2015) 54(10):62-66.

[20] Lim. K, Nagalingam. M and Tan. C, "Design and construction of microstrip UWB antenna with time domain analysis", Progress In Electromagnetics Research M (2008) 3:153164. 
Figures

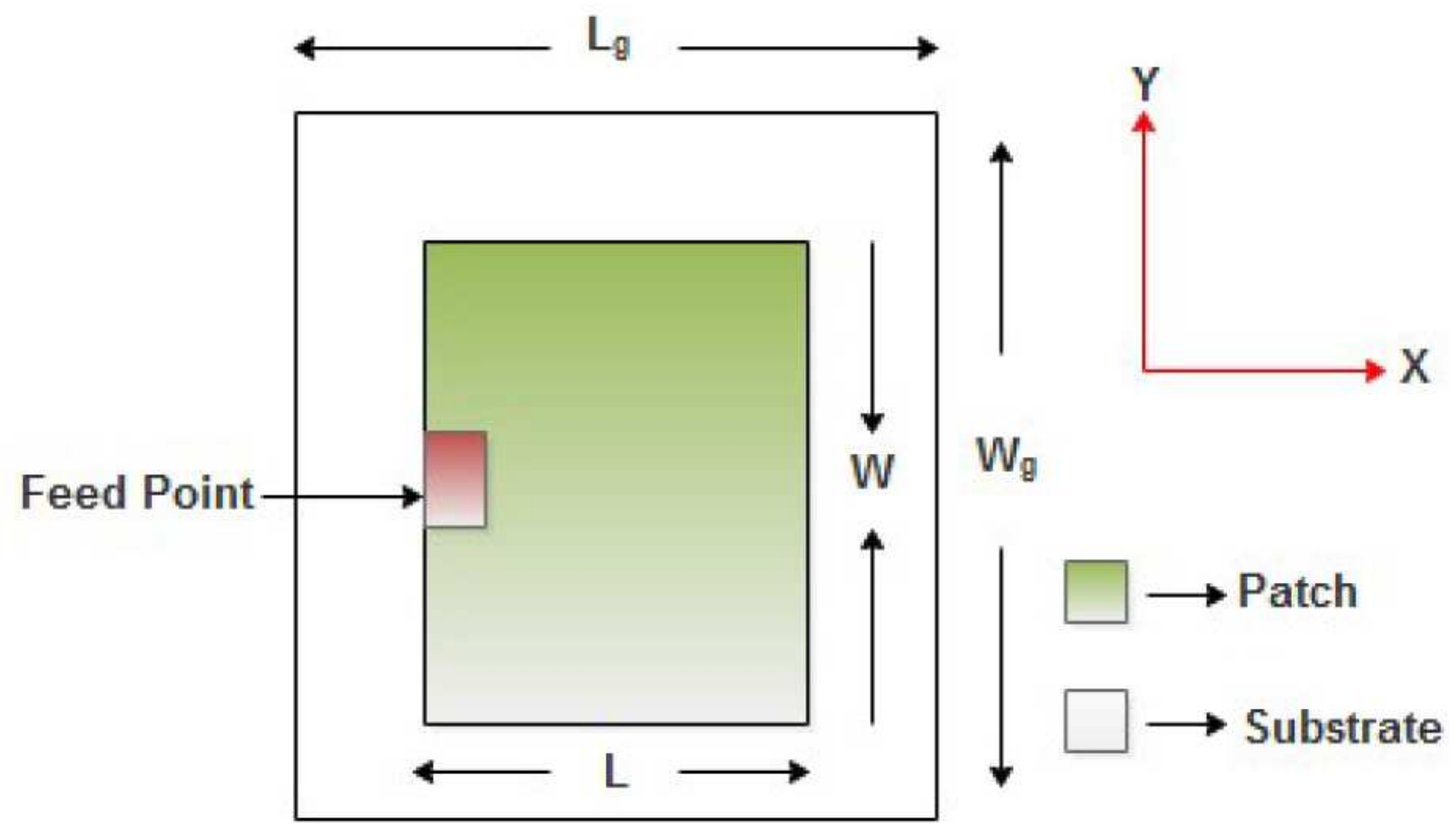

Figure 1

Proposed microstrip antenna design 


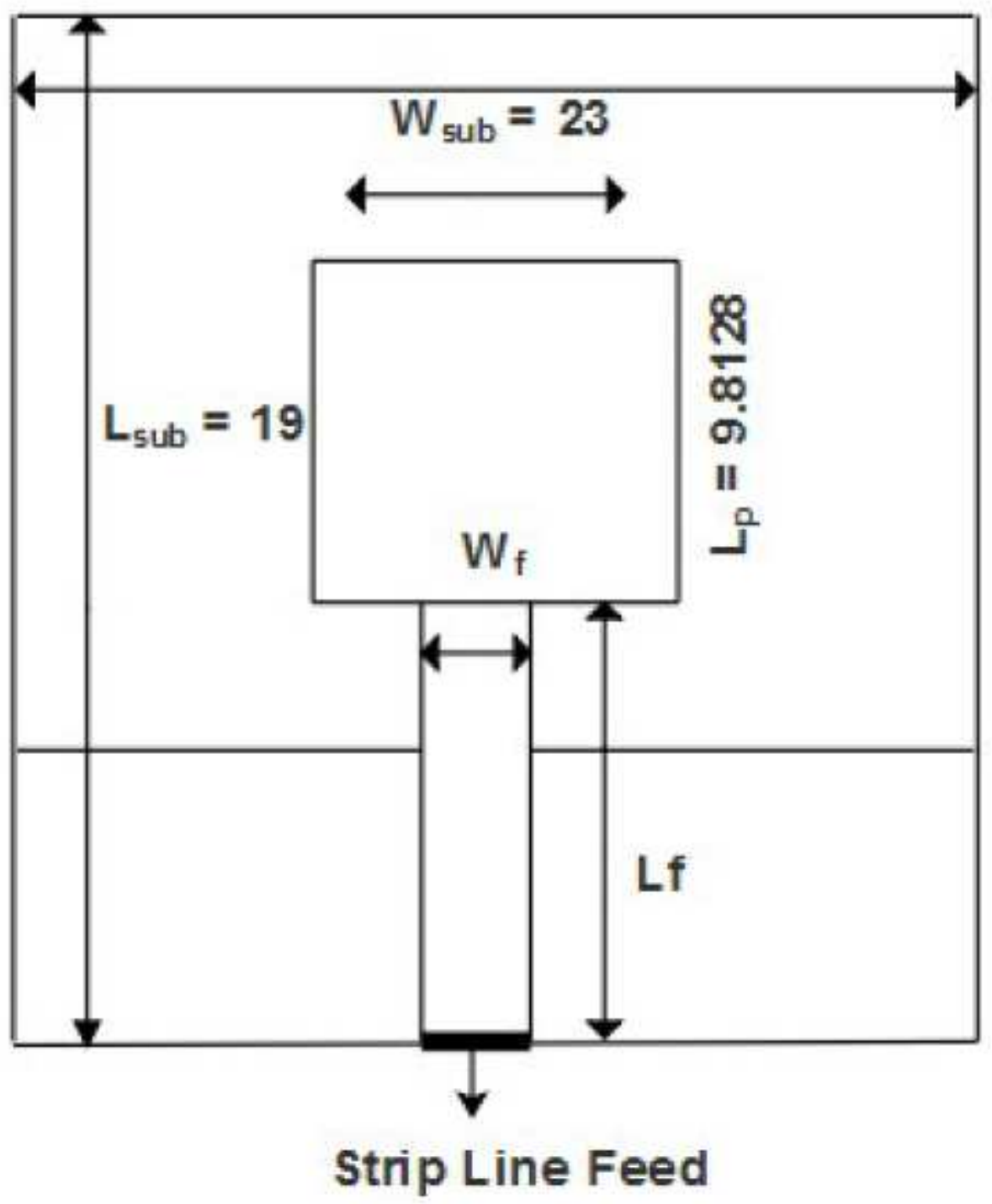

Figure 2

Geometry of the front view for the proposed microstrip antenna 


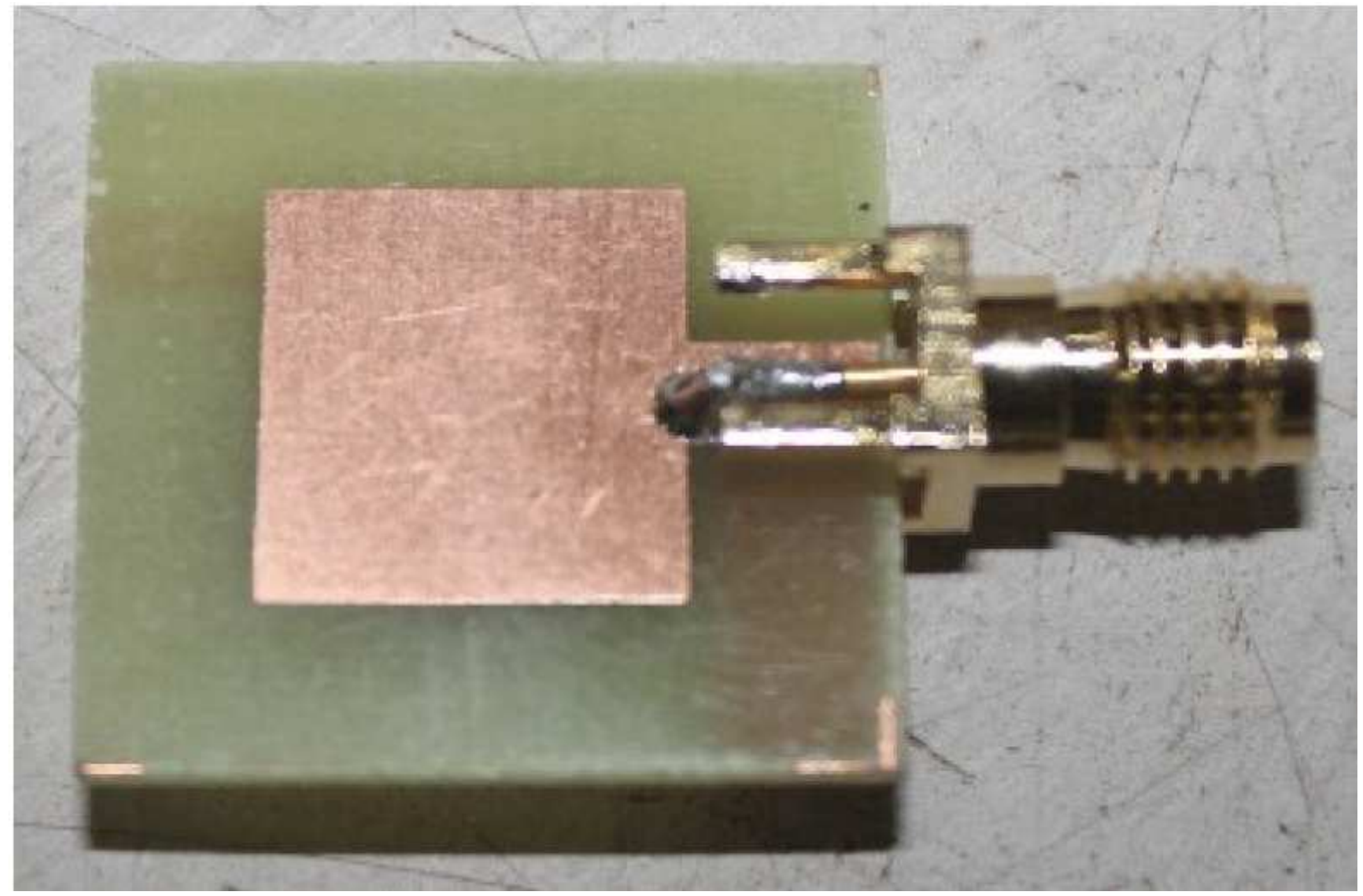

Figure 3

Photography of top view fabricated microstrip antenna 


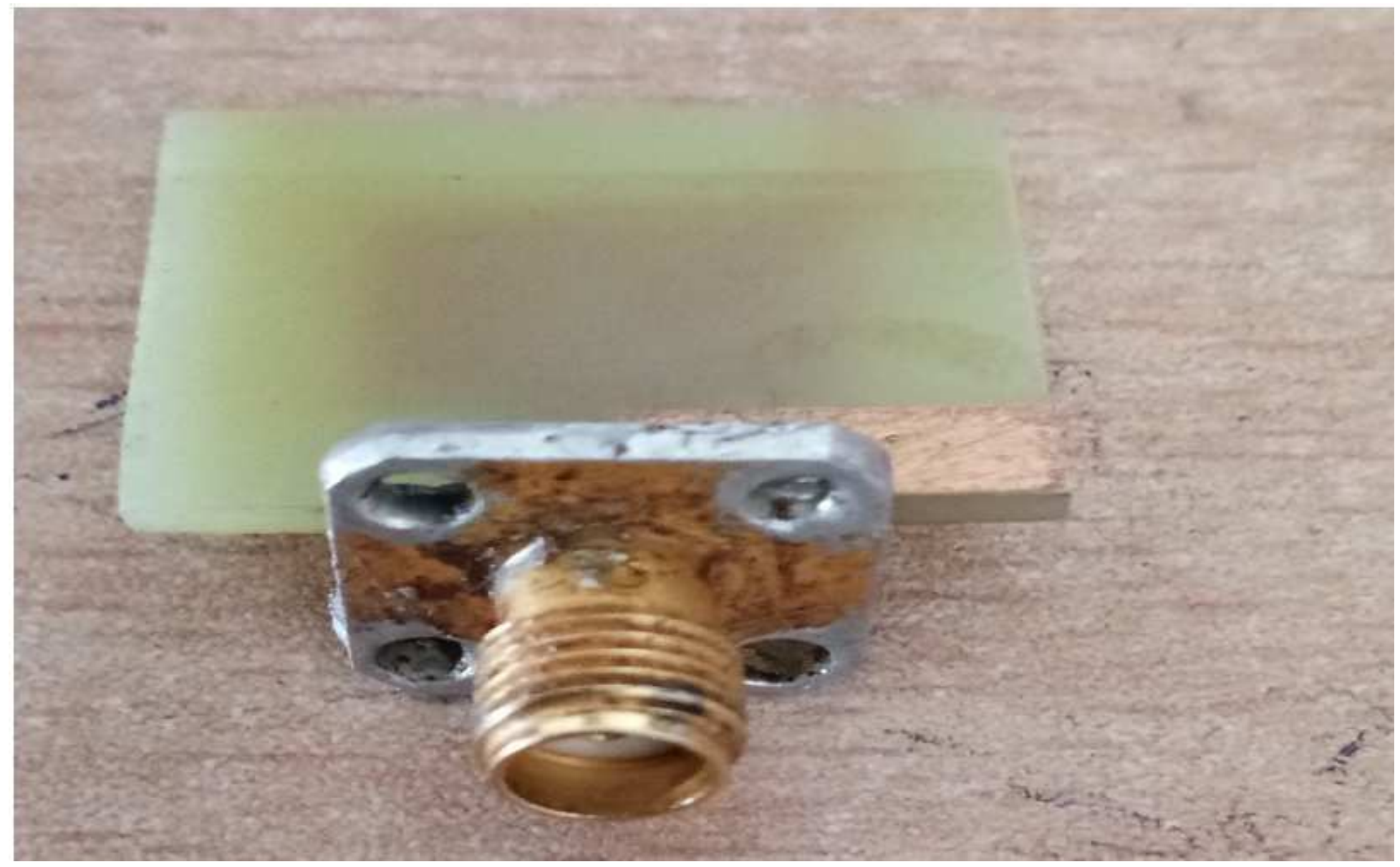

Figure 4

Photography of back view fabricated microstrip antenna 


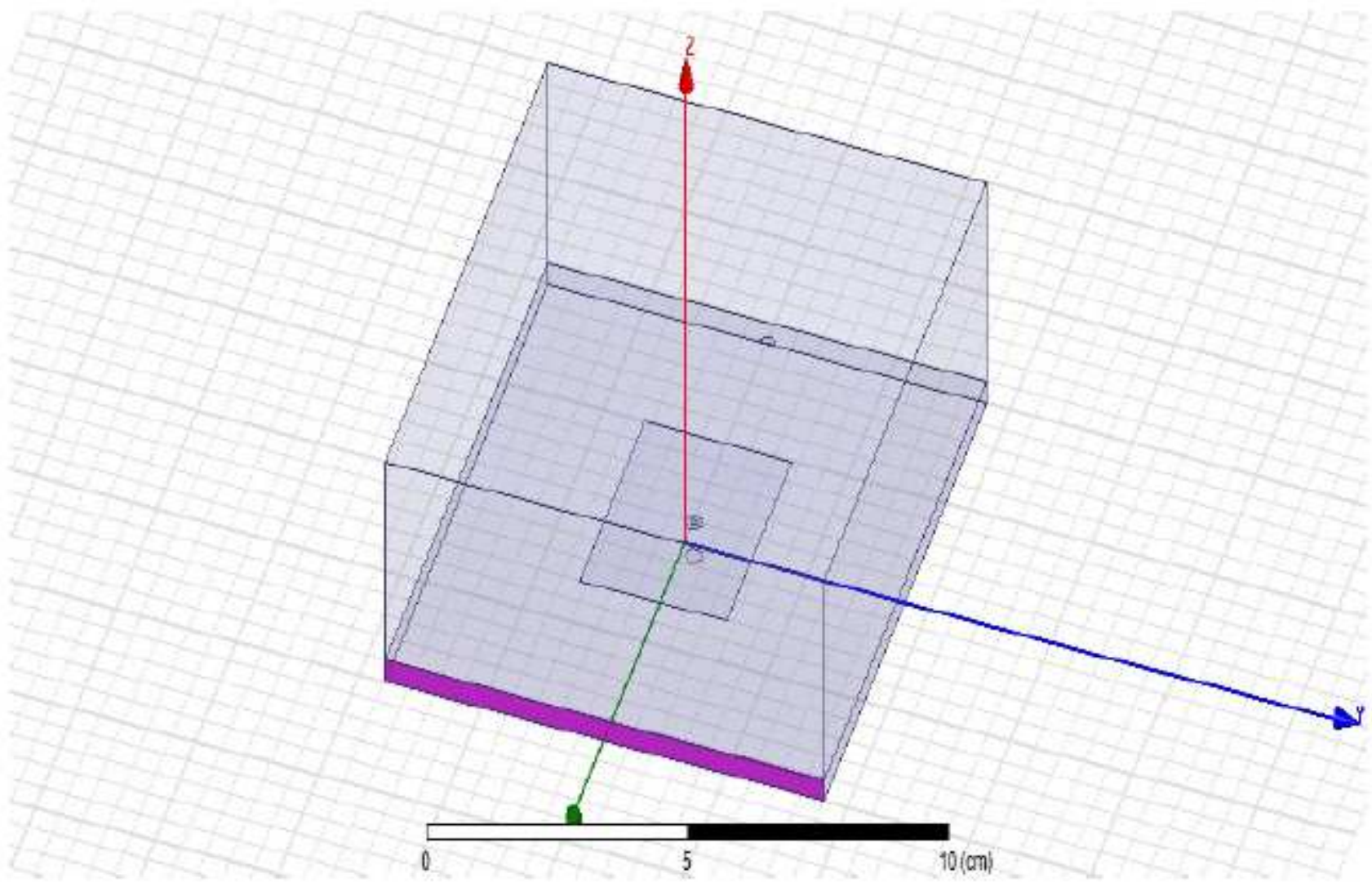

Figure 5

Design of microstrip antenna in the excitation setup 


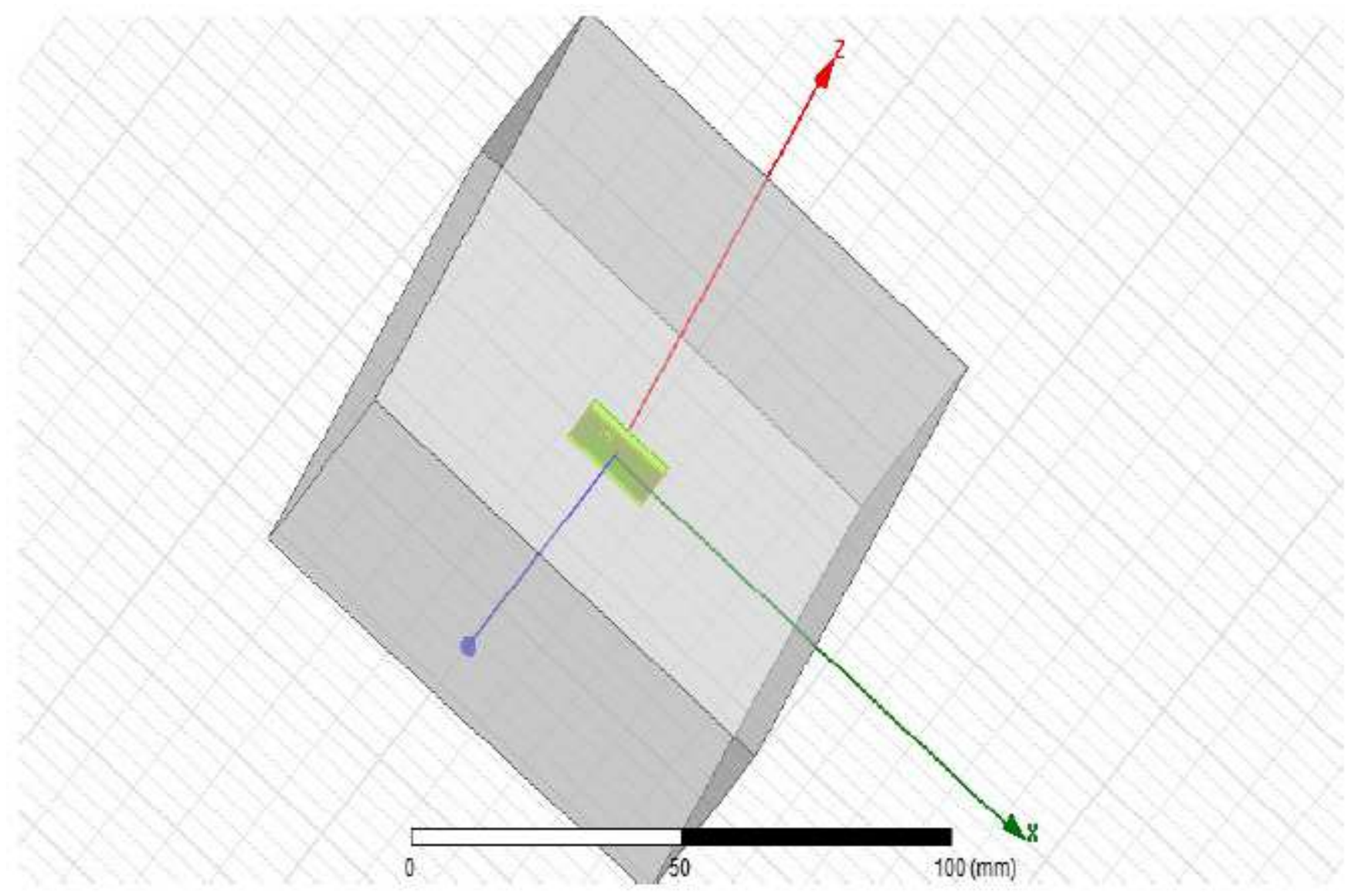

Figure 6

Designed microstrip antenna 


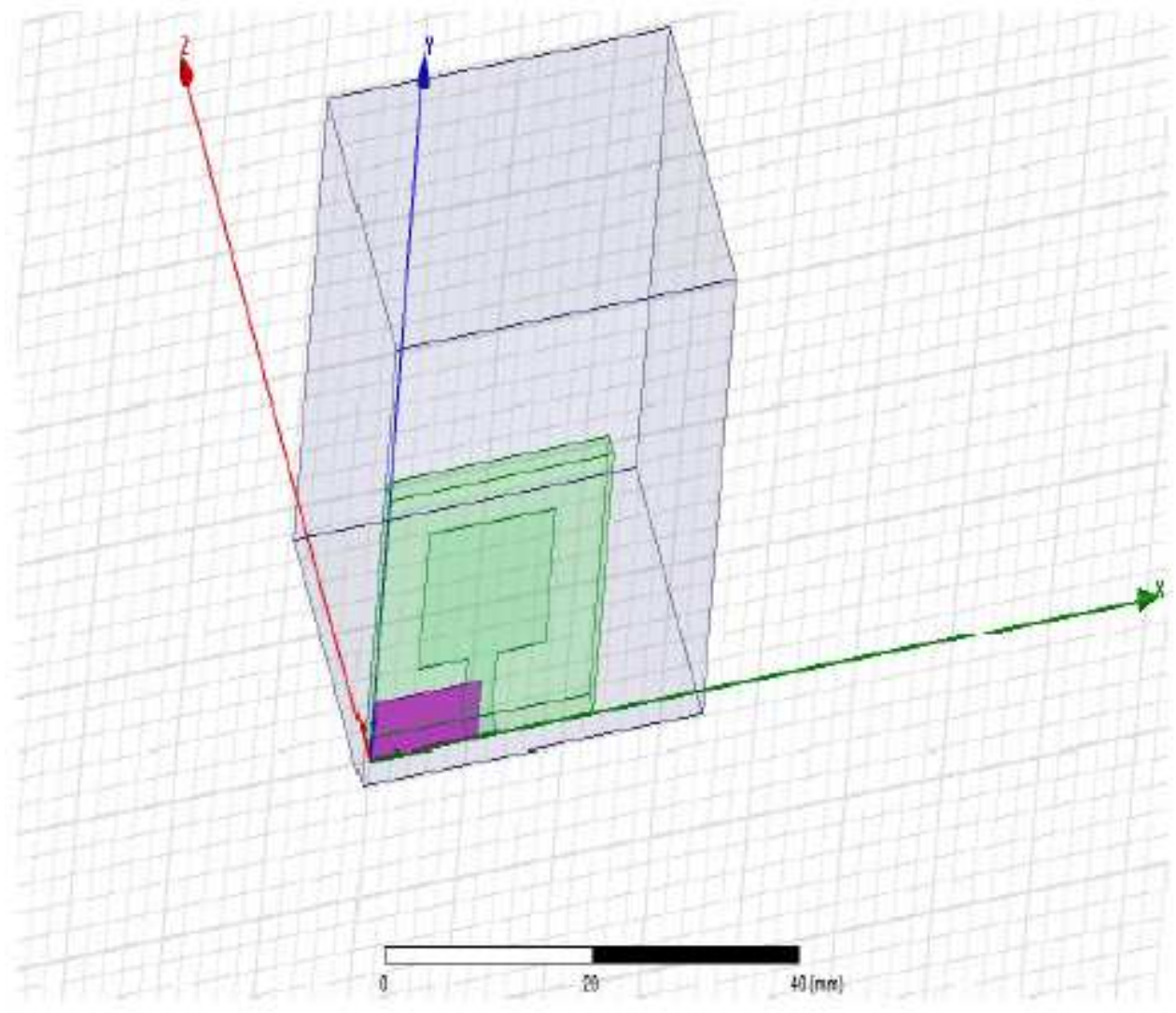

Figure 7

Schematic diagram of iteration for GP length is $4 \mathrm{~mm}$ and GP width is $11 \mathrm{~mm}$ 


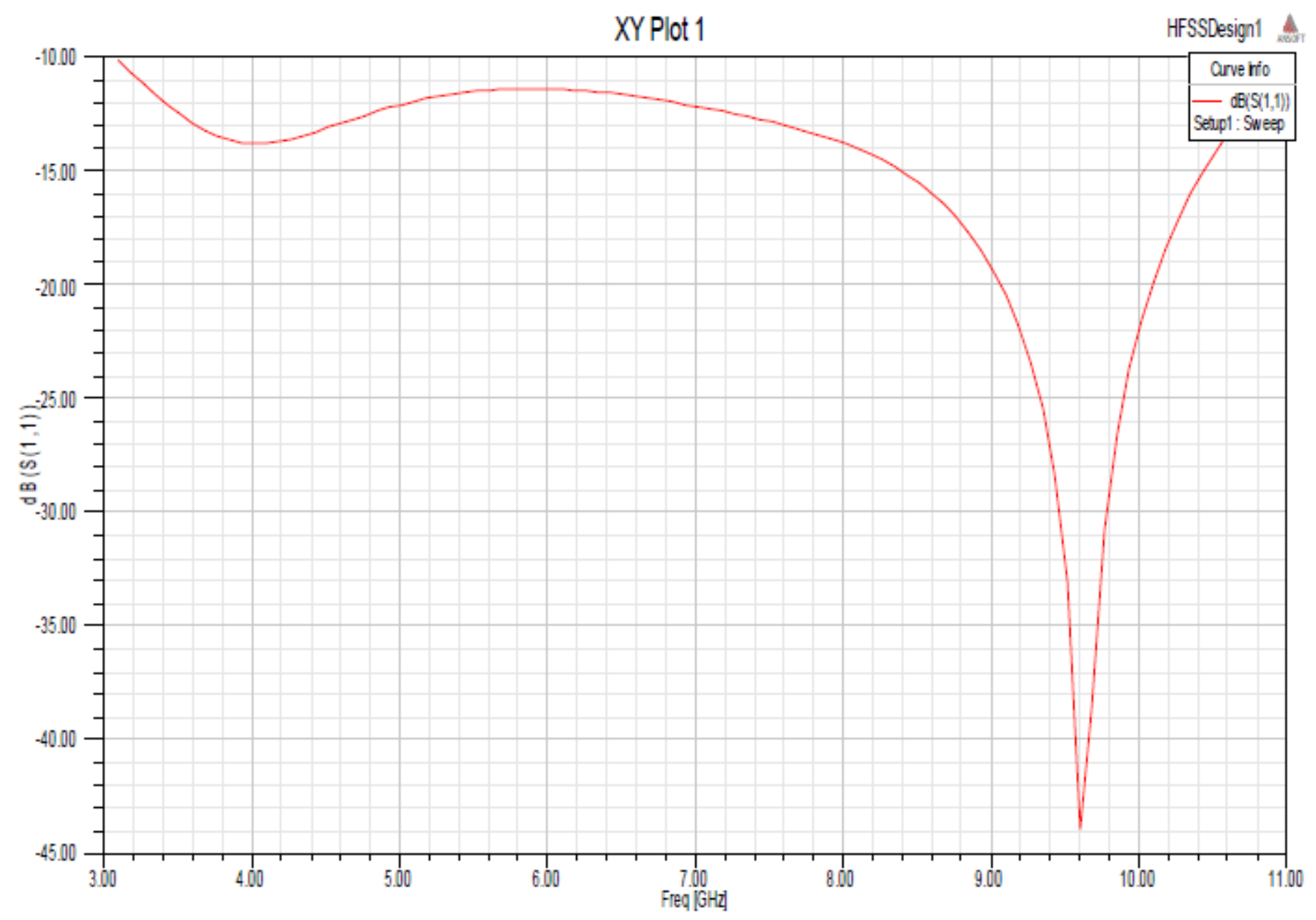

Figure 8

Return Loss Plot for GP length is $4 \mathrm{~mm}$ and the GP width is $11 \mathrm{~mm}$ 


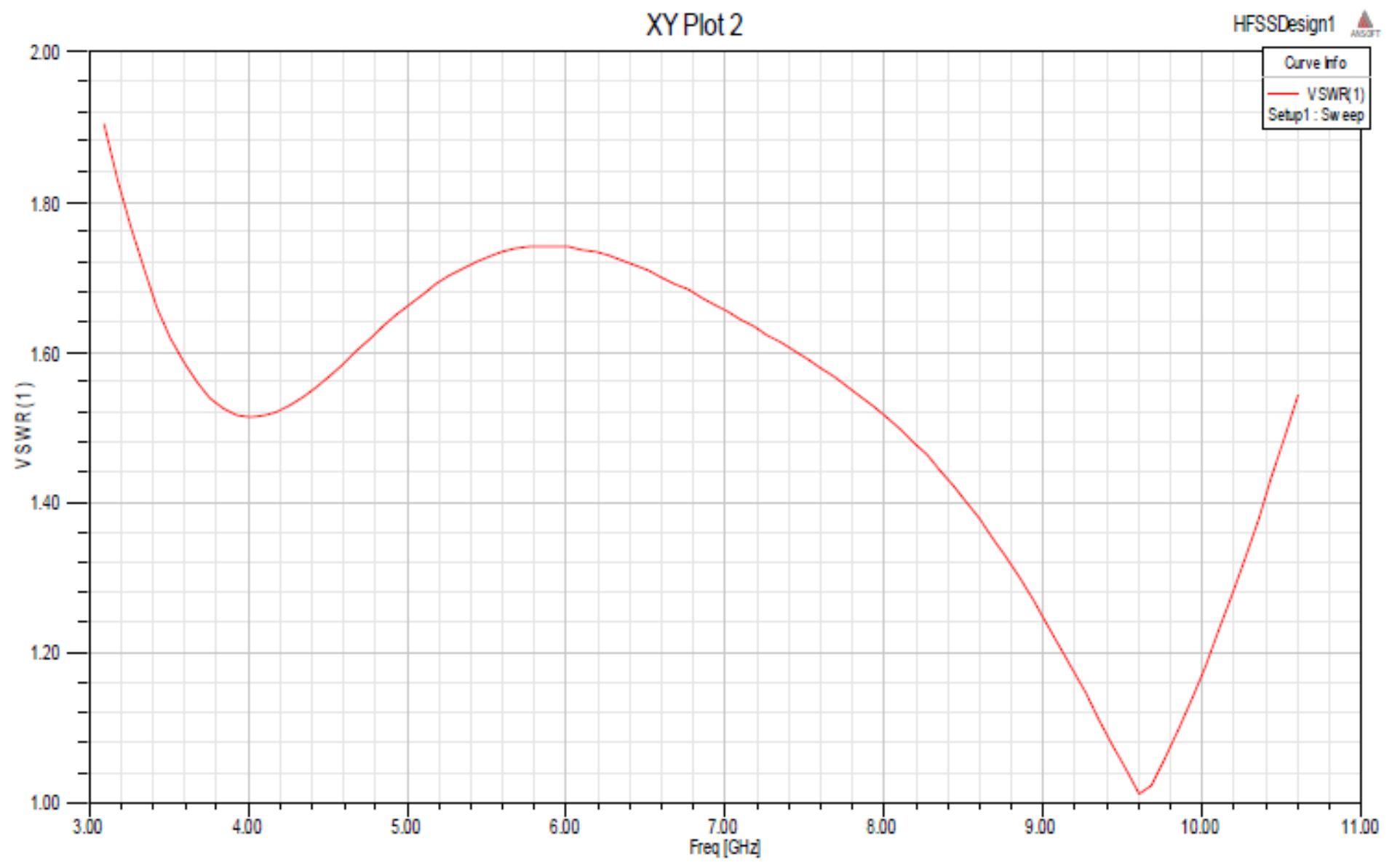

Figure 9

VSWR Plot for GP length is $4 \mathrm{~mm}$ and the GP width is $11 \mathrm{~mm}$ 


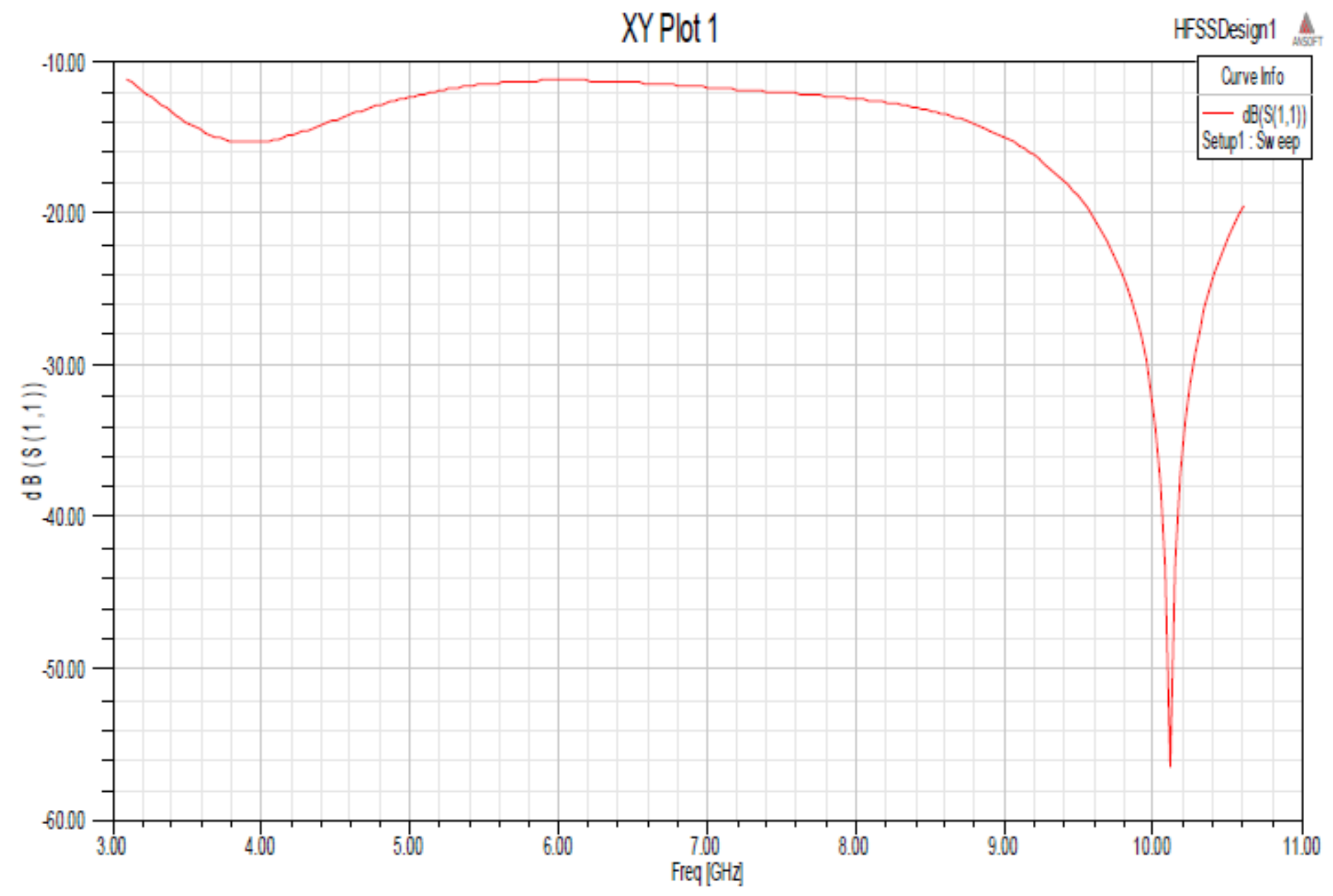

Figure 10

Simulated graph of return loss 


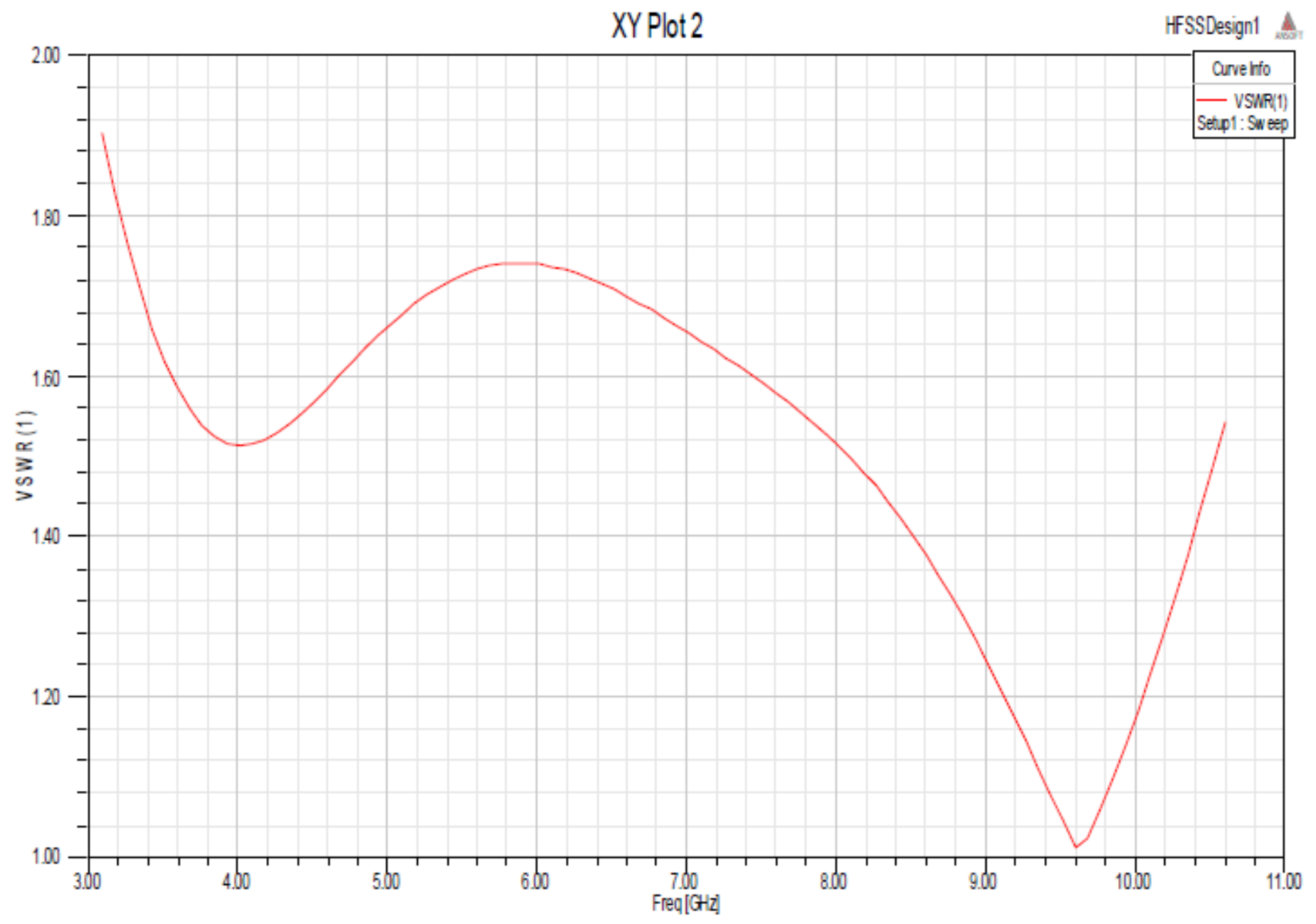

Figure 11

Simulated graph of VSWR 


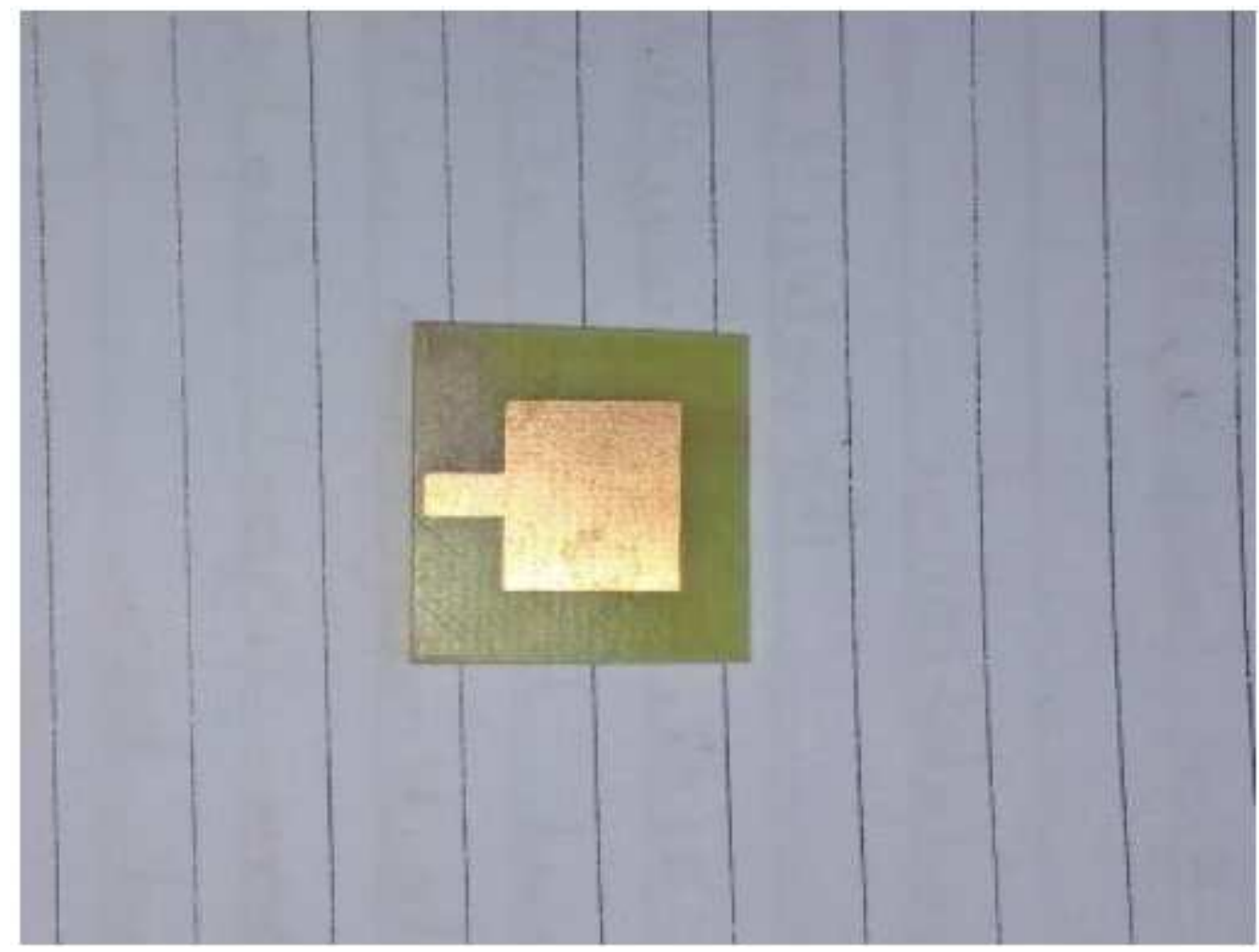

\section{Figure 12}

Fabricated prototype of antenna top view

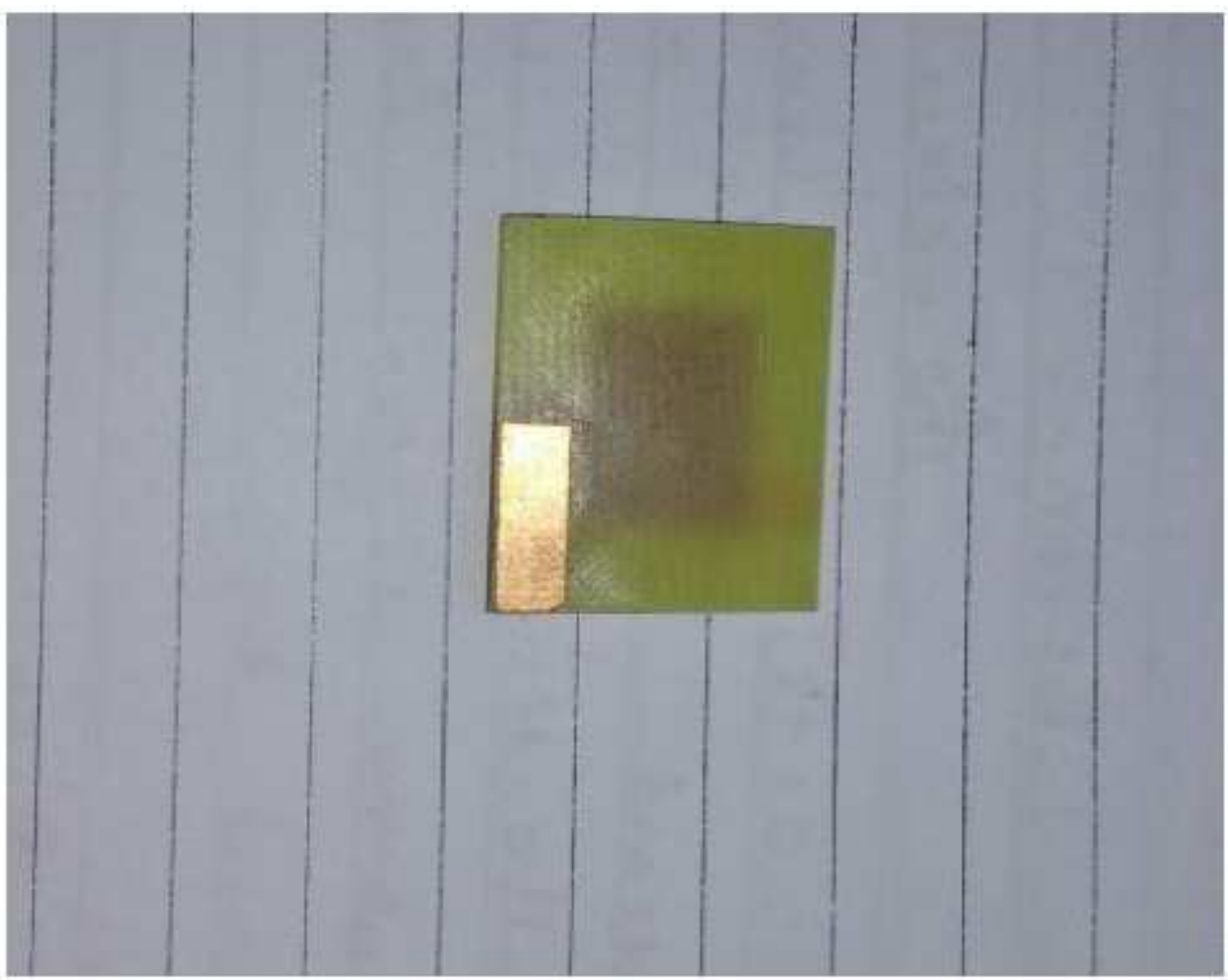

Figure 13

Fabricated prototype of antenna back view 


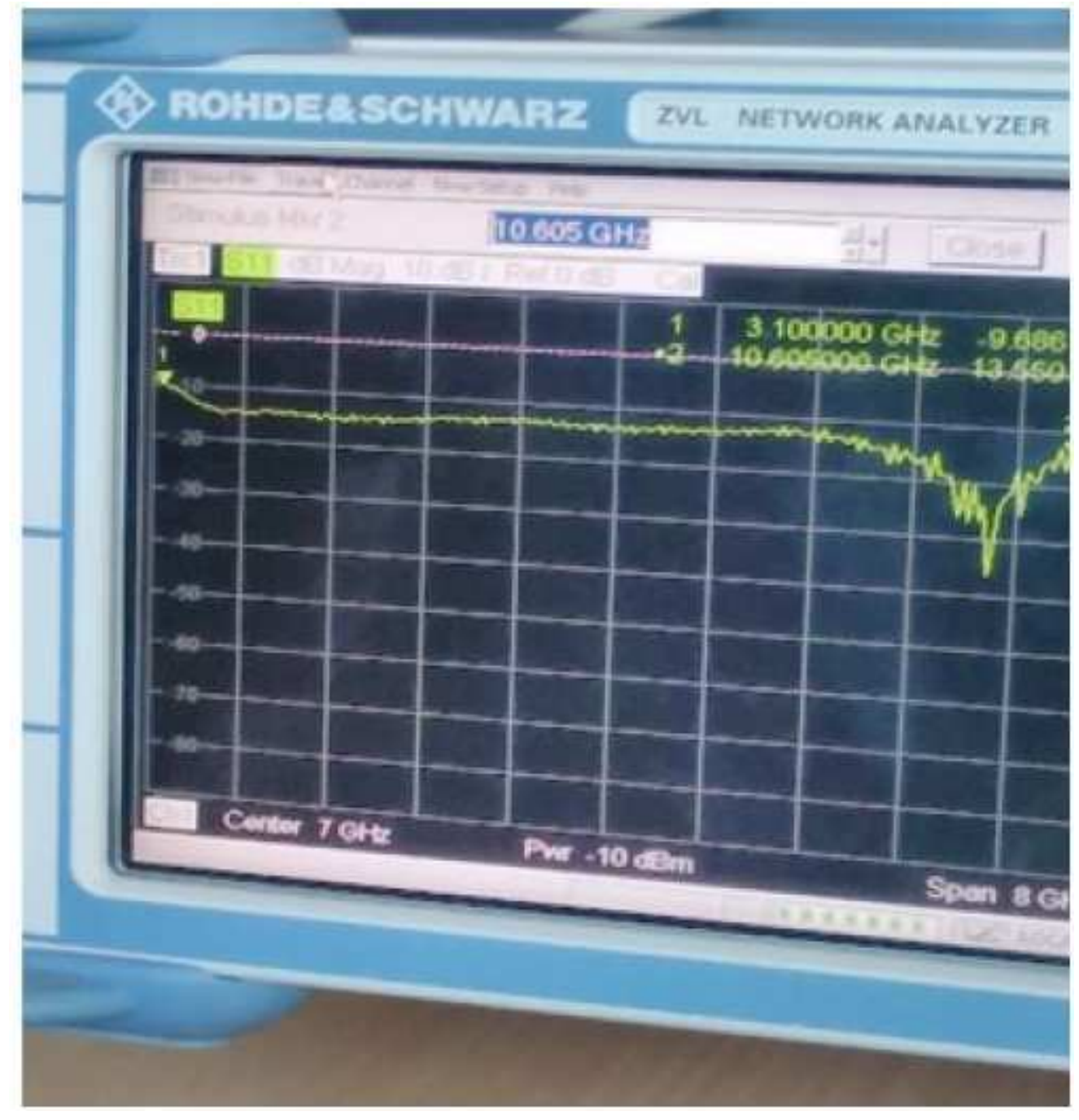

Figure 14

Vector Network Analyzer 